\title{
Ensemble Sensitivity Analysis of the Blocking System over Russia in Summer 2010 $\mathscr{0}$
}

\author{
LISA-ANN QUANDT \\ Institute of Meteorology and Climate Research, Karlsruhe Institute of Technology, Karlsruhe, Germany \\ JULIA H. KELLER \\ World Meteorological Organization, Geneva, Switzerland, and Deutscher Wetterdienst, Offenbach, Germany \\ Olivia MARTIUS \\ Institute of Geography, and Oeschger Centre for Climate Change Research, University of Bern, Bern, Switzerland \\ JOAQUIM G. PINTO \\ Institute of Meteorology and Climate Research, Karlsruhe Institute of Technology, Karlsruhe, Germany \\ SARAH C. JONES \\ Deutscher Wetterdienst, Offenbach, Germany
}

(Manuscript received 18 July 2018, in final form 23 November 2018)

\begin{abstract}
In summer 2010, the weather conditions in the Euro-Russian sector were affected by a long-lasting atmospheric block that led to a heat wave in Russia and floods in Pakistan. Following previous studies describing the block's predictability, the present study aims to investigate uncertainties in the upper-level wave pattern and diabatic processes that were responsible for the block's forecast variability during its onset, mature, and decay phases. With this aim, an ensemble sensitivity analysis (ESA) is performed for three medium-range THORPEX Interactive Grand Global Ensemble multimodel ensemble forecasts, one associated with each phase of the block's life cycle. The ESA revealed that the block's predictability was influenced by forecast uncertainties in the general wave pattern and in the vertically integrated water vapor transport (IVT), used here as a proxy for diabatic processes. These uncertainties are associated with spatial shifts and intensity changes of synoptic waves and IVT during the whole life cycle of the block. During the onset phase, specific features include an Atlantic precursor block and the occurrence of several cyclones. During the mature stage, the blocking ridge itself was highly predictable, while forecast uncertainties in the wave pattern and in IVT primarily were associated with uncertainties in the block's western flank. During the decay phase, the ESA signals were less intense, but the forecast variability significantly depended on the transformation of the block into a high-over-low pattern. It can be concluded that ESA is suitable to investigate the block's forecast variability in multimodel ensembles.
\end{abstract}

Supplemental information related to this paper is available at the Journals Online website: https://doi.org/10.1175/MWR-D-180252.s1.

Corresponding author: Lisa-Ann Quandt, lisa-ann.quandt@ kit.edu

\section{Introduction}

In summer 2010, parts of eastern Europe and Russia were affected by a long-lasting "mega" heat wave from mid-June to mid-August (Dole et al. 2011; Barriopedro et al. 2011; Lau and Kim 2012; Trenberth and Fasullo 2012). Moreover, Pakistan was affected by severe flooding in July (Hong et al. 2011; Houze et al. 2011; Lau and Kim 2012; Martius et al. 2013). These high-impact weather events were associated with an atmospheric block 
(Schneidereit et al. 2012; Lupo et al. 2012). Atmospheric blocks are persistent, quasi-stationary, self-sustaining, spatially extended mid- or high-latitude anticyclones (e.g., Rex 1950; Liu 1994). They influence the extratropical circulation as the flow becomes more meridional, while the jet stream is often decelerated (compared to its previous strength) and split into two branches (e.g., Rex 1950; Arakawa 1952). The jet splitting has an impact on the pathway of arriving eddies that may interact with the blocking system (e.g., Shutts 1983; Mullen 1987). The life cycle of a block is characterized by fluctuations in intensity and spatial extension and can be generally separated into an onset phase, a mature stage, and a decay phase (e.g., Tanaka 1998; Croci-Maspoli et al. 2007).

Large-scale blocks can be related to high-impact weather in the midlatitudes (e.g., Green 1977; Hoskins and Sardeshmukh 1987; Grams et al. 2014). The conditions under the blocking anticyclone are favorable for heat waves in summer, whereas cold waves typically form east of the block in winter (Buehler et al. 2011). Downstream and upstream regions, which are under the influence of the block's flanks (i.e., the adjacent troughs), can be affected by long-lasting and/or extreme precipitation (Carrera et al. 2004) and thus flooding, particularly in summer.

Because of their influence on the extratropical circulation and on high-impact weather, the predictability of blocks is of vital importance. However, their predictability is often low, especially during the onset and decay phases, which correspond to the transition from a zonal to a meridional flow regime (onset) or vice versa (decay; e.g., Tibaldi and Molteni 1990; Frederiksen et al. 2004; Matsueda 2009). If the block is already part of the initial conditions of the forecast, the predictability of the block's maintenance is increased (Tibaldi and Molteni 1990). Pelly and Hoskins (2003a) investigated mediumrange ensemble forecasts from the European Centre for Medium-Range Weather Forecasts (ECMWF) and found that predictions of Euro-Atlantic blocks are skillful relative to climatology out to 10 days and that an ensemble forecast is more skillful than the deterministic one at all lead times. A useful skill beyond 10 days for predictions of blocks was also found by Ferranti et al. (2018), who investigated subseasonal ensemble forecasts. In addition, blocking dynamics are complex because of interactions between different spatial and temporal scales, such as interactions between long-lasting largescale blocks and fast-moving synoptic-scale cyclones (e.g., Berggren et al. 1949; Tsou and Smith 1990; Tracton 1990; Lupo et al. 2007; Pfahl et al. 2015), making a proper representation of blocks in numerical weather prediction models challenging.

The predictability of the 2010 summer block was investigated by Matsueda (2011, hereafter M11) and
Quandt et al. (2017, hereafter Q17). Both studies discussed the forecast variability of the block during different life cycle phases in multimodel ensemble forecasts. They concluded that the onset and the decay phases of the block were not captured by all ensemble members, while the predictability of the trough upstream of the blocking ridge (its western flank) was low during the mature stage. The forecast variability of the block during its three life cycle phases is also illustrated in Fig. 1 (based on the forecasts used in Q17). During the onset phase of the block, the ensemble spread is primarily increased in upstream regions (Fig. 1a). As the ridge amplifies at $40^{\circ} \mathrm{E}$, the ensemble spread also increases there (Figs. 1b,c). During the mature stage, the forecast variability of the block's western flank around $0^{\circ}$ is clearly visible (Figs. 1d-f). As for the onset phase, the ensemble spread during the decay phase is larger upstream of the block and also increased along the block itself (Figs. 1g-i). Q17 discussed in detail that this forecast variability influenced the surface weather conditions. During the onset phase of the block, the evolution of the heat wave was dependent on the block's development, meaning that surface temperatures remained moderate in ensemble members without the block. During the mature stage, heavy precipitation over Europe varied substantially between the ensemble members. This variability was related to the position, tilt, and amplitude of the block's western flank. During the decay phase of the block, the end of the heat wave was somewhat independent from the block's decay, since the surface temperatures decreased in both members with and without the block. In members with a block, this variability was related to a spatial shift of the blocking ridge, so that the upper-level geopotential height wave and the surface temperature wave were no longer in phase.

While Q17 provided a description of the block's forecast variability, it did not address the causes of this variability. In the present study, we investigate possible reasons for the variability and address the following research questions:

- Which uncertainties in the synoptic-scale flow pattern were associated with uncertainties in the structure of the 2010 summer block?

- Can the uncertainties associated with the block's predictability be related to dynamical processes?

- Are the results associated with the block's forecast variability different among the three phases of the block's life cycle?

With this aim, we use the ensemble sensitivity analysis (ESA; Torn and Hakim 2008) to study dependencies between the representation of the block and synoptic-scale 
Onset Phase

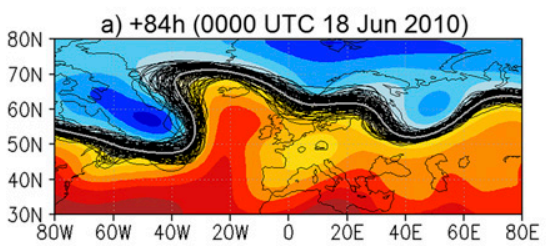

b) $+132 \mathrm{~h}(0000$ UTC 20 Jun 2010)

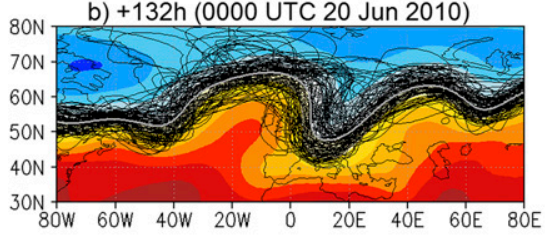

Mature Stage

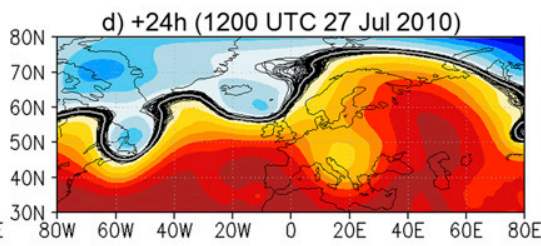

Decay Phase

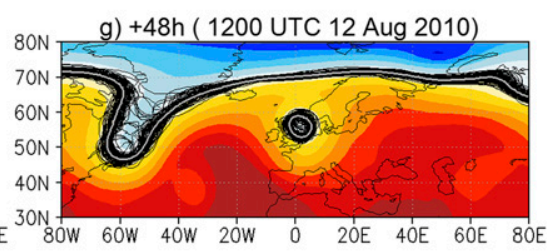

e) $+72 \mathrm{~h}(1200$ UTC 29 Jul 2010)

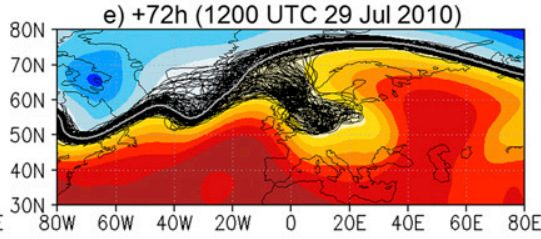

h) +96h (1200 UTC 14 Aug 2010)

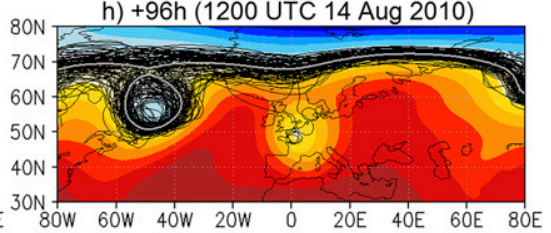

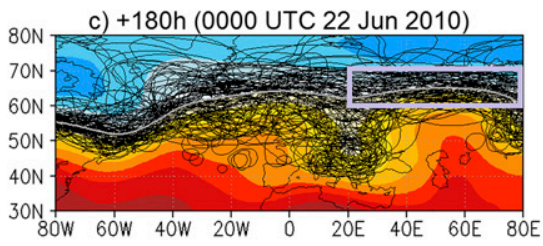
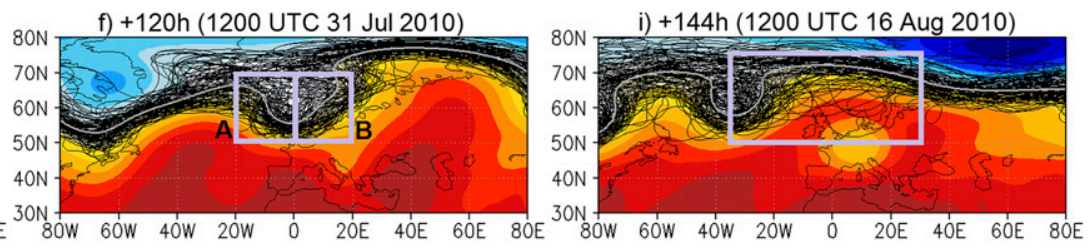

\begin{tabular}{lc|c|c|c|c|c|}
\hline $\mathbf{5 3 0 0}$ & 5400 & 5500 & $\mathbf{5 6 0 0}$ & $\mathbf{5 7 0 0}$ & $\mathbf{5 8 0 0}$ & $\mathbf{5 9 0 0}$
\end{tabular}

FIG. 1. The $5600 \mathrm{gpm}$ isolines of all ensemble members (black contours), $5600 \mathrm{gpm}$ isoline of ensemble mean (gray contour), and 500-hPa geopotential height (shading in gpm) from the forecasts initialized at (a)-(c) 1200 UTC 14 Jun (capturing the onset phase of the block), (d)-(f) 1200 UTC 26 Jul (capturing the mature stage), and (g)-(i) 1200 UTC 10 Aug 2010 (capturing the decay phase). Purple boxes in (c),(f),(i) mark the areas that were used to calculate the metrics for the ESA approach.

flow features in medium-range ensemble forecasts. To our best knowledge, ESA is used here for the first time to investigate the forecast variability of a blocking system within a multimodel ensemble. Magnusson (2017) and Parker et al. (2018) applied ESA to investigate blocking systems, but with single model ensembles. Parker et al. (2018) investigated precursors for Greenland blocks, while Magnusson (2017) identified blocks as sources of uncertainty in medium-range forecasts.

This paper is structured as follows. Section 2 describes the datasets and methods used in this study. For the onset phase of the block, a synoptic overview and sensitivity results with a subsequent discussion are presented in section 3. Section 4 addresses the mature stage of the block, while section 5 addresses its decay phase. Conclusions are summarized in section 6 .

\section{Data and methods}

\section{a. Data}

We selected one 10-day ensemble forecast from the THORPEX Interactive Grand Global Ensemble (TIGGE; Swinbank et al. 2016) multimodel ensemble prediction system (EPS) for each phase of the block. We followed Q17 and used the same 10-day ensemble forecasts; thus, we focused on the synoptic time scale (see appendix). The simulations from the ECMWF (51 members), the National Centers for Environmental Prediction (NCEP; 21 members), and the Met Office (UKMO; 24 members) were included. The ensemble forecasts were obtained in 12-h forecast steps with an interpolated spatial resolution of $1^{\circ}$ in longitude and latitude. An overview of the initialization times of the forecasts is provided in Table 1. The selected forecasts are characterized by a large ensemble spread, indicating that they capture a large diversity in forecasting the shape, position, and amplitude of the block (e.g., Figs. 5, 11, and 16 in Q17). Regarding the onset phase, some members show the development of the block, while others do not (Q17). The same is true for the decay phase of the block (Q17). For the mature stage, the ensemble members show different developments for the block's western flank (Q17). Further information about the selection of the EPSs and the forecasts themselves can be found in the appendix.

The initial conditions of the control forecasts from the ECMWF, NCEP, and UKMO were used as analysis data. We used an unweighted mean of these three analyses (hereafter referred to as analysis), since only small differences for the considered synoptic fields were found. 
TABLE 1. Forecast initialization times and metric times (see section $2 b$ ) for the three investigated phases of the block's life cycle.

\begin{tabular}{lll}
\hline \hline Life cycle phase & \multicolumn{1}{c}{ Initialization time } & \multicolumn{1}{c}{ Metric time } \\
\hline Onset phase & 1200 UTC 14 Jun 2010 & 0000 UTC 22 Jun 2010 \\
Mature stage & 1200 UTC 26 Jul 2010 & 1200 UTC 31 Jul 2010 \\
Decay phase & 1200 UTC 10 Aug 2010 & 1200 UTC 16 Aug 2010 \\
\hline
\end{tabular}

\section{b. Ensemble sensitivity analysis}

\section{1) BACKGROUND}

The ESA is a correlation method developed to quantify the influence of initial condition uncertainties on forecast variability (e.g., Torn and Hakim 2008; Torn 2010b; Zheng et al. 2013), but can also contribute to process understanding (e.g., Schumacher 2011; Keller 2017). In this study, ESA is used for the first time to identify synoptic features that are relevant for the predictability of the 2010 summer block using a multimodel ensemble.

The basic idea behind ESA is that small deviations of a state variable from the ensemble mean at time $t$ are correlated to deviations of a metric from the ensemble mean at time $t+\Delta t$ (being defined as metric time). Following Torn and Hakim (2008), the sensitivity is defined as

$$
\text { sens }=\frac{\partial \mathbb{J}}{\partial \mathbb{X}} \times \sigma_{x}=\frac{\operatorname{cov}(\mathbb{J}, \mathbb{X})}{\operatorname{var}(\mathbb{X}, \mathbb{X})} \times \sigma_{x},
$$

where $\mathbb{X}$ is an independent state variable, $\mathbb{J}$ the metric, and $\sigma_{x}$ the standard deviation across ensemble members of the state variable. For an individual ensemble member, $\mathbb{X}$ is a $2 \mathrm{D}$ array of a state variable [see section $2 b(3)$ ] and $\mathbb{J}$ a single value [see section $2 b(2)]$. The term $\partial \mathbb{J} / \partial \mathbb{X}$ is normalized with the standard deviation of the state variable $\sigma_{x}$. Therefore, changes in the metric are associated with changes in the state variables by $1 \times \sigma_{x}$, allowing the direct comparison between different state variables (Torn and Hakim 2008).

The applicability of the ESA approach is limited for different reasons. First, the ESA considers a linear relationship between the metric and the state variable. Although the error growth within medium-range forecasts is nonlinear, the method still offers valuable insights, since linearly derived sensitivity structures can have an impact on the highly nonlinear development of weather systems [e.g., as shown for explosively deepening extratropical cyclones; Chang et al. (2013)]. Second, since ESA is a correlation method, it does not necessarily imply causality. Still, it is possible to separate synoptically meaningful from spurious correlations when taking the synoptic development of single ensemble members into account. In addition, the results are also sensitive to the choice of EPSs (in our case, ECMWF, NCEP, and UKMO), as they provide forecasts of different ensemble sizes.

Here, we use ESA to investigate causes for the forecast variability of the block discussed by Q17. There, the ensemble forecasts were clustered on the basis of an empirical orthogonal function analysis, where each cluster represented different synoptic development scenarios of the block. For consistency, we use the clustering times from Q17 as metric times (Table 1): that is, the time for which we want to identify how the status of the flow was affected by the synoptic developments at earlier forecast times. The sensitivities were calculated in 12-hourly time steps from 1 up to 6 days before metric time (cf. Chang et al. 2013). We limit our investigation to forecast times beyond $48 \mathrm{~h}$, as by that time, we expect the "memory of initial perturbations" not to affect the results anymore (Torn and Hakim 2008). Following Torn and Hakim (2008), only sensitivities that are statistically significant on a $95 \%$ level are considered. Statistical significance was estimated using a two-tailed $t$ test (with 96 ensemble members; 1.985 is the critical value for $t$ ).

\section{2) METRICS}

To assess the impact of forecast fields at earlier time steps on the block at metric time, we need metrics that suitably capture the characteristics of the block. For the three investigated life cycle phases of the block, different requirements were imposed on the metrics. For the onset and decay phases, the metric should represent the amplitude of the blocking ridge. For the mature stage, the western flank variability should be captured by the metric. Therefore, different metrics were chosen for the different stages in the block's life cycle. All metrics use the Z500 field, as this variable is commonly used to investigate blocks (e.g., Tsou and Smith 1990; Buehler et al. 2011) as well as for the calculation of blocking indices (e.g., Tibaldi and Molteni 1990). In the Z500 field, blocks correspond to positive geopotential height anomalies.

For the block's onset phase, we have chosen the $\mathrm{Z} 500$ maximum within a box $\left(60^{\circ}-70^{\circ} \mathrm{N}, 20^{\circ}-80^{\circ} \mathrm{E}\right)$ located at the northern edge of the block in the analysis as the metric (Fig. 1c). With a trough or a less amplified ridge in the box, the metric values are low; with a strongly amplified ridge (corresponding to a block), the metric values are high.

During the mature stage of the block, we chose a metric that reflects the position and/or tilt of the trough upstream of the blocking anticyclone, addressing the variability in the block's western flank. We use the difference between the spatially averaged Z500 in two 
adjacent boxes $\left(\mathrm{A}: 50^{\circ}-70^{\circ} \mathrm{N}, 20^{\circ} \mathrm{W}-0^{\circ}\right.$; B: $50^{\circ}-70^{\circ} \mathrm{N}$, $0^{\circ}-20^{\circ} \mathrm{E}$; Fig. 1f). The spatial mean of box B was subtracted from the spatial mean of box A. Positive values of the metric (corresponding to higher Z500 in box A than in box B) reflect an eastward shift of the trough or cyclonic wave breaking (CWB). Negative values of the metric (corresponding to higher Z500 in box B, compared to box A) reflect a westward shift of the trough or anticyclonic wave breaking (AWB). Values close to zero correspond to a meridionally oriented trough centered at $0^{\circ}$ (in the middle of boxes $\mathrm{A}$ and $\mathrm{B}$ ).

The mean of $\mathrm{Z500}$ in a box $\left(50^{\circ}-75^{\circ} \mathrm{N}, 35^{\circ} \mathrm{W}-30^{\circ} \mathrm{E}\right)$ was chosen to represent the block during the decay phase (Fig. 1i). High values of the metric correspond to high Z500, indicating that the block still exists. Low values of the metric go with low Z500, reflecting a weakening or even dissipation of the block.

For the three different phases of the block, several metrics were tested. The metrics discussed above were found to be the most suitable in terms of statistical significance (on a $95 \%$ confidence level), continuity (time longevity), and clarity (spatial consistency) of the resulting ESA signals. As metrics based on area averages had been used in previous studies (Torn and Hakim 2008; Torn 2010a), we first tested area averages for different box sizes. Calculating the difference of two adjacent box means was also tested for the onset and the decay phases. Thereby, the boxes were not adjacent in the zonal direction, but in the meridional (cf. Pelly and Hoskins 2003b) in order to capture the overturning features of the blocking ridge. However, this was less successful for the onset and decay phases than with the simple single box means. A reason could be that the overturning of the block was not sufficiently pronounced at the investigated metric times. Finally, we also compared the results with the Z500 maximum as metric to those with the Z500 mean as metric (same box sizes). For the block's onset phase, the signals were similar, but some improvement could be observed for the Z500 maximum. However, there was no significant improvement for the decay phase or the mature stage of the block. Thus, we decided to use the maximum Z500 only to investigate the forecast variability during the block's onset phase.

\section{3) State variables}

The following state variables are used in the ESA approach:

- 500-hPa geopotential height (Z500)

- Mean sea level pressure (MSLP)

- Vertically integrated water vapor transport (IVT)

The choice of Z500 is trivial, as it is a standard variable for investigating blocks [see section $2 b(2)$ ]. Moreover, it is expedient to investigate the sensitivities to Z500 and MSLP, since these fields are also used to provide a synoptic overview for the forecast periods (see sections 3a, 4a, and 5a). Thus, we can connect our findings from the sensitivity analysis with the synoptic evolution.

Since diabatic processes are important for blocking development (e.g., Pfahl et al. 2015), we also investigate their relevance for the predictability of the block. With this aim, a proxy of warm conveyor belts (WCBs) was chosen, as WCBs themselves cannot be calculated from the TIGGE dataset directly. Thus, we used the IVT following the definition of Lavers et al. [2012; Eq. (1) in section 2 therein] to gain some insight into the role of diabatic processes for blocking predictability. Areas of high IVT generally correspond to atmospheric rivers (AR), which are filaments of high water vapor transport in the troposphere and are typically synoptic scale in length but mesoscale in width. They normally do not exist as isolated phenomena, but are strongly connected to WCBs and thus to extratropical cyclones (Neiman et al. 2008; Dacre et al. 2015; Dettinger et al. 2015). Precipitation was also tested as proxy for latent heat release, but only small-scale and noisy sensitivity signals were obtained. A summary of how ESA signals can be interpreted in association with the metrics and state variables is illustrated in Fig. 2. In Fig. 2a, a positive sensitivity coincides with a ridge in the Z500 field, while a negative sensitivity lies within a trough downstream. In this case, the block could be located downstream of this ridgetrough structure. The pattern reflects that an amplified (weaker) ridge-trough couplet is associated with an increased (decreased) metric. In Fig. 2b, a negative sensitivity is located in a ridge and a positive sensitivity in a trough, meaning that an amplified (weaker) ridge-trough couplet would imply decreased (increased) metric values. In Fig. 2c, the positive sensitivity shows the area where a higher (lower) IVT is associated with an increase (decrease) in the metric, while in Fig. 2d, the negative sensitivity shows the area where a higher (lower) IVT is associated with a decrease (increase) in the metric.

\section{Onset phase of the block}

\section{a. Synoptic overview}

In the analysis, the development of the block in the 500-hPa geopotential height field (Z500) is visible in Fig. 3. On 15 June, a trough-ridge couplet is present between $80^{\circ} \mathrm{W}$ and $0^{\circ}$ (Fig. 3a). The trough centered at about $60^{\circ} \mathrm{W}$ coincides with a surface cyclone. At $0^{\circ}$, there is a cutoff low, also associated with low surface pressure. The presence of upstream surface cyclones before and during blocking formation was investigated in previous studies (e.g., Colucci 1985; Tsou and Smith 1990) and 


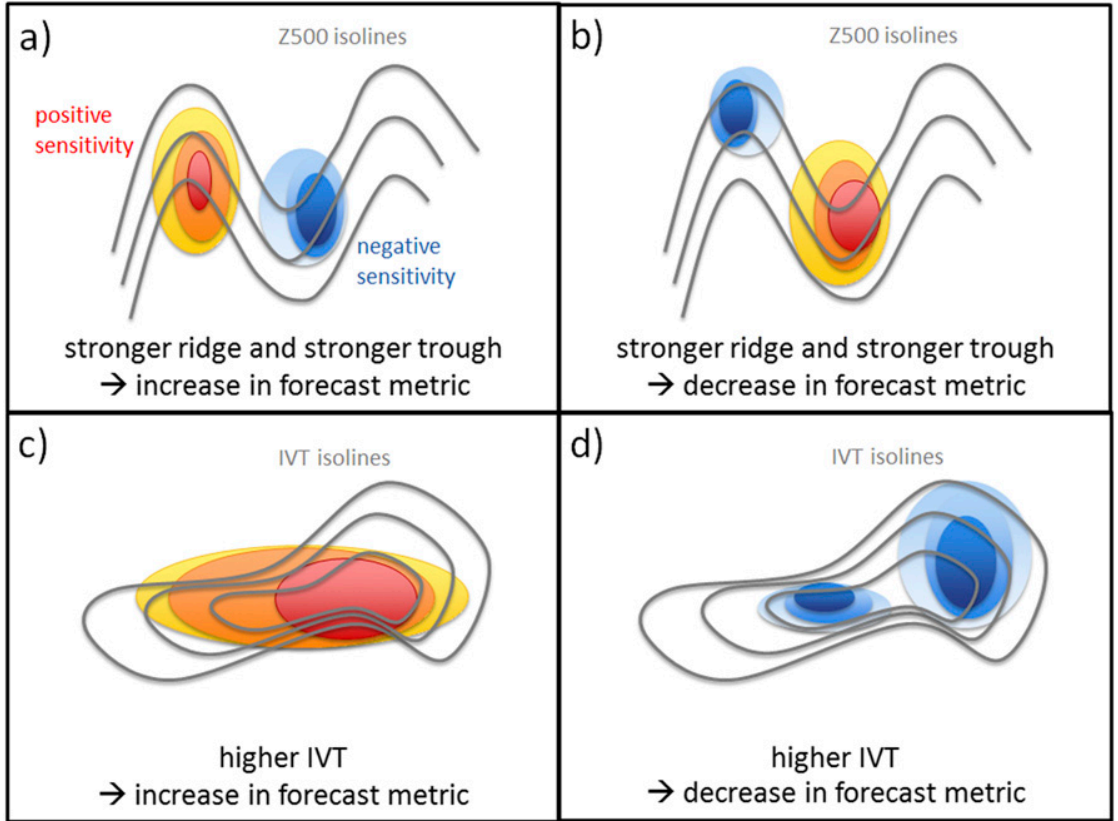

FIG. 2. Schematic illustrating how the metric changes depend on changes in Z500 and IVT. The colored areas show the sensitivities (blue for negative and red for positive sensitivities). The gray isolines show the ensemble mean of the corresponding state variables. (a),(b) Sensitivities to Z500. (c),(d) Sensitivities to IVT. For these sensitivity patterns, the block (which is represented by the metric) could be downstream of these signals.

denoted as "cyclone-block coupling" (Colucci 1987). In this coupling process, the surface cyclones act as energy and potential vorticity (PV) sources for the block, as low-PV air from lower latitudes is transported along the eastern flank of the cyclones into the blocking area (Lejenäs 1977; Colucci 1985). The troughs and ridges over Europe between $20^{\circ}$ and $80^{\circ} \mathrm{E}$ (where strong surface cyclones are absent at this time) are less amplified, compared to the wave pattern upstream. On 16 and 17 June, the axis of the Atlantic ridge is tilted eastward, and the surface cyclone between $40^{\circ}$ and $60^{\circ} \mathrm{E}$ deepens, while the wave pattern downstream amplifies (Figs. 3b,c). On 18 June, the Atlantic ridge shows an overturning to the west, indicating CWB (Fig. 3d) that develops further in the next $24 \mathrm{~h}$ (Fig. 3e). Between 20 and 22 June, the amplitude of the Atlantic ridge decreases, while the ridge at $40^{\circ} \mathrm{E}$ intensifies (Figs. $3 \mathrm{f}-\mathrm{h}$ ). This ridge at $40^{\circ} \mathrm{E}$ is the developing block that will be associated with the Russian heat wave. It evolves from the mobile ridge at $10^{\circ} \mathrm{E}$ on 17 June (Fig. 3c) and becomes stationary at $40^{\circ} \mathrm{E}$ on 19 June and then amplifies (Figs. 3e-h).

\section{b. Sensitivity results}

For the onset phase, positive (negative) sensitivities show where an increase in the state variable is associated with an increase (decrease) in the forecast of the Z500 maximum between $20^{\circ}$ and $80^{\circ} \mathrm{E}$.

On 21 June ( $-24 \mathrm{~h}$ before metric time), a large positive sensitivity to $\mathrm{Z} 500$ is centered at $50^{\circ} \mathrm{E}$, forming a dipole with a large negative sensitivity upstream, centered at $10^{\circ} \mathrm{E}$ (Fig. 4a). The large positive sensitivity signal can be traced back to 19 June $(-72 \mathrm{~h})$ at $65^{\circ} \mathrm{N}, 40^{\circ} \mathrm{E}$ (Fig. $4 \mathrm{c}$ ). This sensitivity signal coincides with the blocking ridge developing on 20 June. The large negative sensitivity can be traced back to 18 June ( $-96 \mathrm{~h}$; Fig. 4c) and lies in the trough upstream of the blocking ridge. From 20 June $(-48 \mathrm{~h})$ back to 18 June $(-96 \mathrm{~h})$, there are positive sensitivity values over Greenland (Figs. 4b-d). These sensitivities coincide with a cyclonically breaking wave (Fig. 4d). On 17 June $(-120 \mathrm{~h})$, the sensitivities are smaller and weaker (Fig. 4e), compared to the other forecast lead times (Figs. 4a-d).

The sensitivities to Z500 indicate that an amplified Atlantic ridge, which undergoes wave breaking, on 18 and 19 June and an amplified trough-ridge pattern between $0^{\circ}$ and $80^{\circ} \mathrm{E}$ from $19 \mathrm{June}$ onward are associated with an amplified blocking ridge over Russia on 22 June.

The sensitivity pattern of MSLP is quite similar to that of Z500 (Figs. $4 \mathrm{f}-\mathrm{j})$. On 21 June $(-24 \mathrm{~h})$, a dipole of a western negative sensitivity and an eastern positive 
a) 0000 UTC 15 Jun 2010

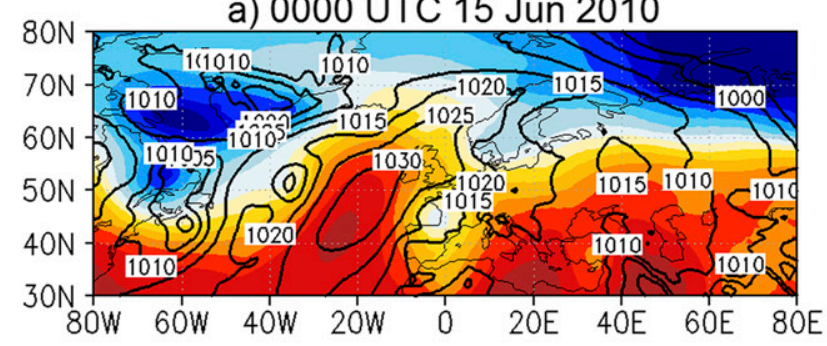

e) 0000 UTC 19 Jun 2010)

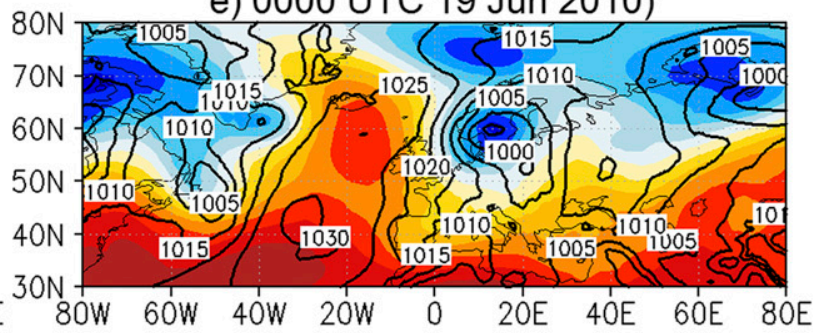

b) 0000 UTC 16 Jun 2010

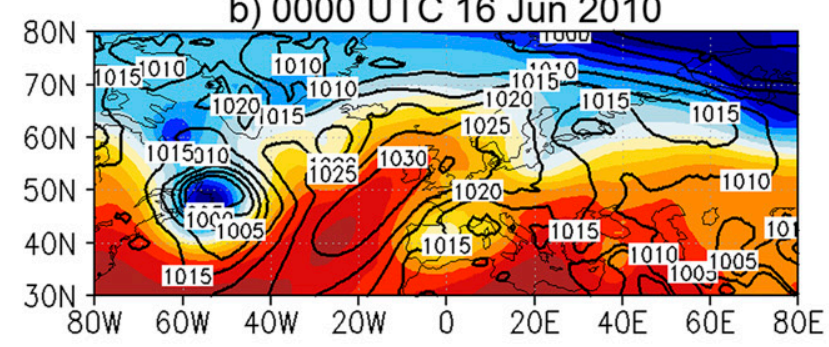

f) 0000 UTC 20 Jun 2010)

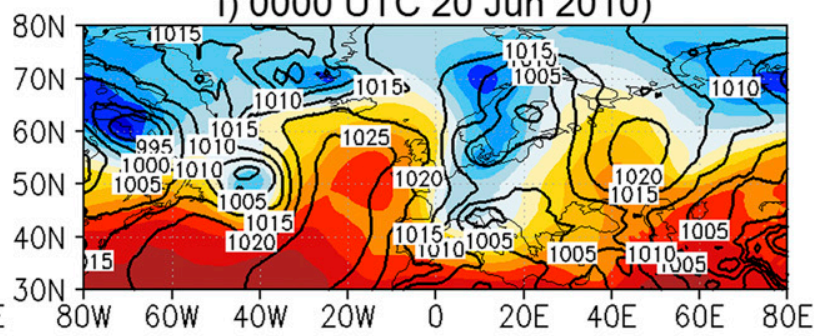

c) 0000 UTC 17 Jun 2010

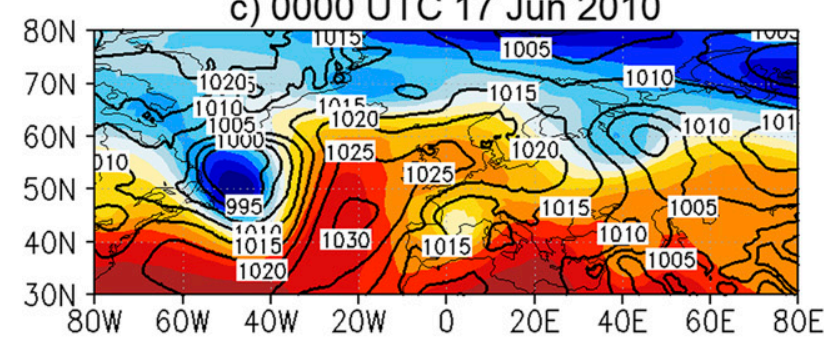

g) 0000 UTC 21 Jun 2010
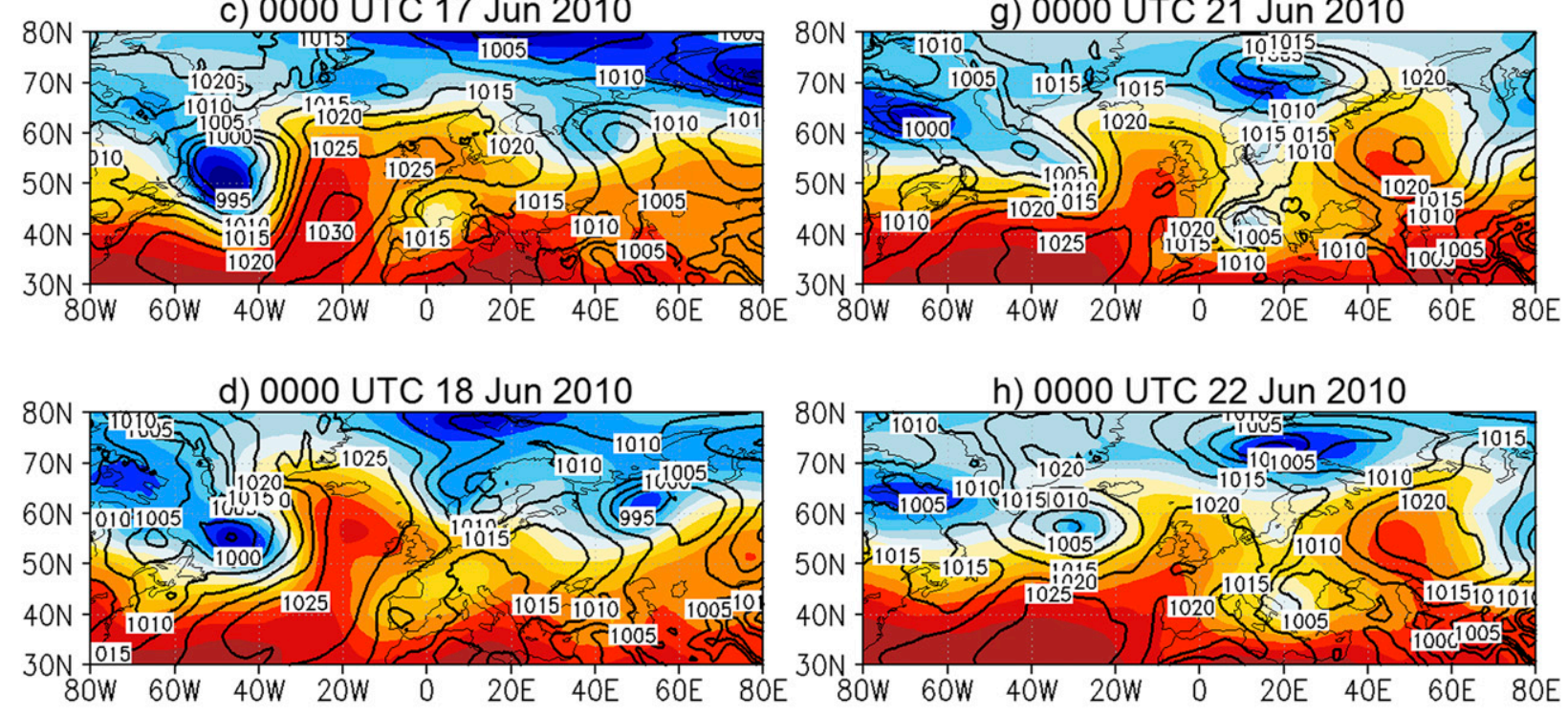

h) 0000 UTC 22 Jun 2010

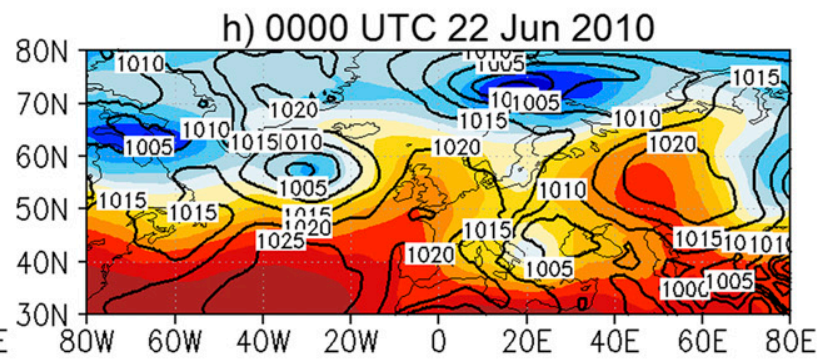

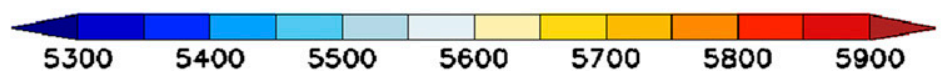

FIG. 3. The 500-hPa geopotential height (shading in gpm) and MSLP (contours in hPa) from the analysis from (a) 0000 UTC 15 Jun to (h) 0000 UTC 22 Jun 2010.

sensitivity can be seen over Europe (Fig. 4f). This dipole is already visible at shorter lead times (Figs. 4g,h). The positive sensitivity is located within a high pressure system that corresponds to the blocking system. The negative sensitivity is located within an area of low pressure. On $18(-96 \mathrm{~h})$ and 19 June $(-72 \mathrm{~h})$, a large positive sensitivity is found over Greenland. Another negative sensitivity is present within a low pressure system between Canada and Greenland (Figs. 4f,g).
The MSLP sensitivities indicate that an intensified high pressure system over Europe and deeper upstream lows on 20 and 21 June, as well as higher surface pressure over Greenland on 18 and 19 June, are associated with an amplified blocking ridge at $40^{\circ} \mathrm{E}$ on 22 June.

The sensitivities to the third state variable IVT are spatially patchier, compared to the Z500 and MSLP sensitivities (Figs. 4k-o). This could be expected, as the IVT field has a much higher small-scale variability. 
Z500

a) -24h (0000 UTC 21 Jun 2010)

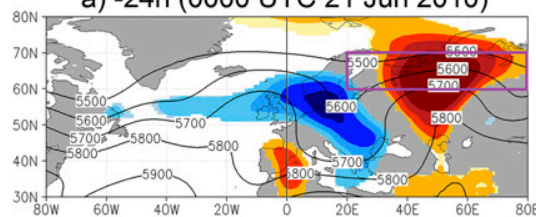

b) $-48 \mathrm{~h}$ (0000 UTC 20 Jun 2010)

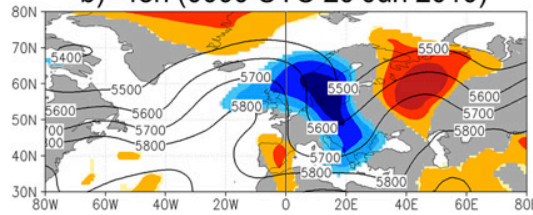

c) $-72 \mathrm{~h}$ (0000 UTC 19 Jun 2010)

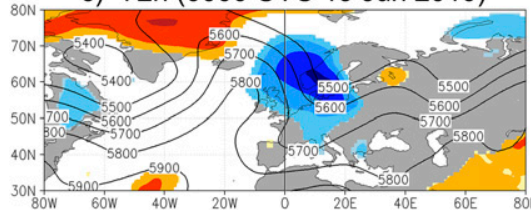

d) -96h (0000 UTC 18 Jun 2010)

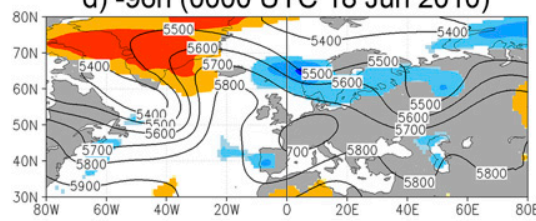

e) $-120 \mathrm{~h}$ (0000 UTC 17 Jun 2010)

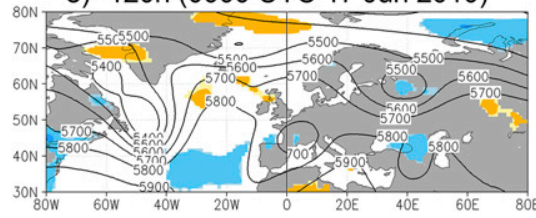

MSLP

f) -24 h (0000 UTC 21 Jun 2010)

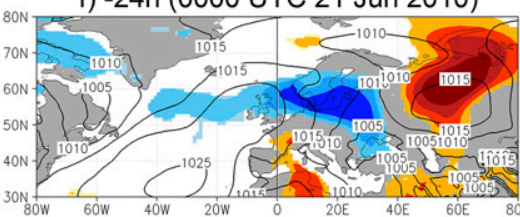

g) $-48 \mathrm{~h}$ (0000 UTC 20 Jun 2010)

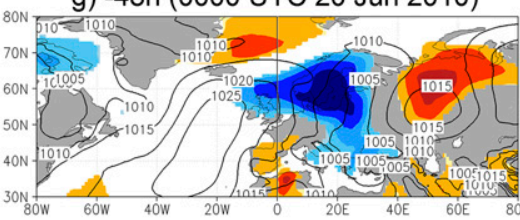

h) $-72 \mathrm{~h}$ (0000 UTC 19 Jun 2010)

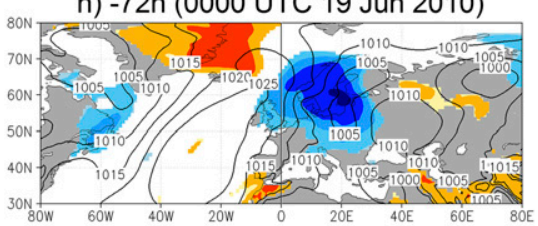

i) $-96 \mathrm{~h}$ (0000 UTC 18 Jun 2010)

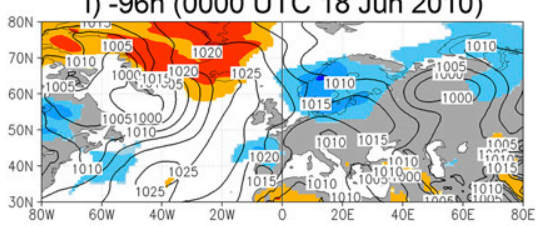

j) -120h (0000 UTC 17 Jun 2010)

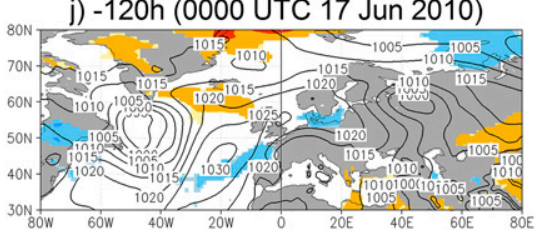

IVT

k) -24h (0000 UTC 21 Jun 2010)

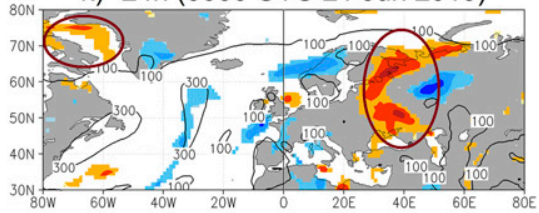

I) $-48 \mathrm{~h}$ (0000 UTC 20 Jun 2010)

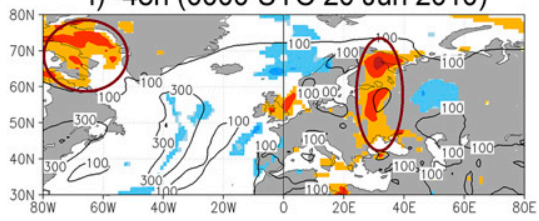

m) -72h (0000 UTC 19 Jun 2010)

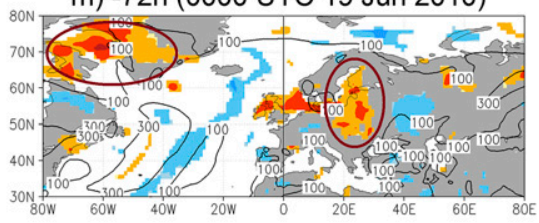

n) -96h (0000 UTC 18 Jun 2010)

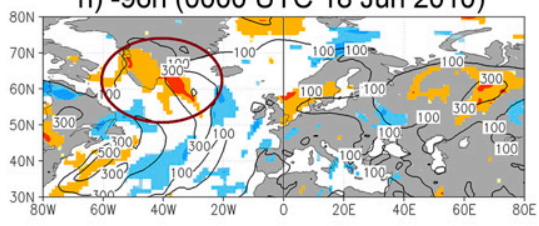

o) -120h (0000 UTC 17 Jun 2010)

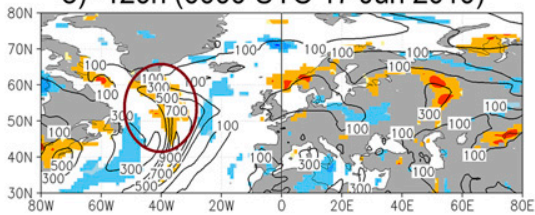

$\begin{array}{lllllllllll}-25 & -20 & -15 & -10 & -5 & 0 & 5 & 10 & 15 & 20 & 25\end{array}$

FIG. 4. Statistically significant sensitivities (shading in gpm) of the metric (maximum 500-hPa geopotential height) at 0000 UTC 22 Jun 2010 (the metric time) to (a)-(e) the 500-hPa geopotential height (Z500), (f)-(j) the MSLP, and (k)-(o) the IVT from -24 h (0000 UTC 21 Jun 2010) back to -120 h (0000 UTC 17 Jun 2010) before metric time, plus the corresponding ensemble mean of Z500 (contours in gpm), of MSLP (contours in $\mathrm{hPa}$ ), and of IVT [contours in $\mathrm{kg} \mathrm{(m} \mathrm{s})^{-1}$ ]. Purple box in (a) shows the area that was considered to calculate the metric. Brown circles highlight the IVT sensitivities that are discussed in the text.

Therefore, only the strongest signals are discussed. On 21 June $(-24 \mathrm{~h})$, the largest positive sensitivity can be found at $40^{\circ} \mathrm{E}$ (Fig. 4k). This feature can be traced back to 19 June $(-72 \mathrm{~h})$, shifted to the west (Fig. $4 \mathrm{~m})$. The second largest sensitivity is located west of Greenland (Figs. 4k-m) and appears already on 17 June $(-120 \mathrm{~h})$ south of Greenland around $55^{\circ} \mathrm{N}, 40^{\circ} \mathrm{W}$ (Fig. 4o), coinciding with high IVT values.

In total, four spatially coherent signals can still be identified: one west of Greenland, one over Europe, and two over the Atlantic. On $17(-120 \mathrm{~h})$ and 18 June $(-96 \mathrm{~h})$, higher IVT values along the U.S. East Coast and toward south Greenland are associated with an amplified blocking ridge at $40^{\circ} \mathrm{E}$ on 22 June. From 21 June $(-24 \mathrm{~h})$ back to 19 June $(-72 \mathrm{~h})$, the positive sensitivities west of Greenland (around $70^{\circ} \mathrm{W}$ ) and over Europe (around $30^{\circ} \mathrm{E}$ ) indicate where high IVT is positively correlated with the amplitude of the blocking ridge over the Euro-Russian sector.

In conclusion, the forecast variability of the block during its onset phase is correlated with the amplitude of the ridge over Russia (which evolves to the blocking ridge) and with amplitudes of an adjacent trough and of an Atlantic ridge upstream of the blocking system. Especially, the Atlantic ridge seems to play a crucial role. 
These relations can be also found on the surface regarding high and low pressure systems. Given the significant sensitivities to IVT (used as proxy for ARs or WCBs), the predictability of diabatic processes may be also important for the forecast at longer lead times. For instance, there seems to be a connection between the Atlantic ridge and high IVT over the Atlantic and west of Greenland (which coincides with the overturning part of the ridge).

\section{c. Discussion}

The block developed from a mobile ridge that became stationary at $40^{\circ} \mathrm{E}$ and amplified. This amplification was not consistently predicted within the ensemble members, indicating that there were members with and without blocking (Figs. 1a-c). The predictability of the block was dependent on the prediction of an Atlantic ridge with $\mathrm{CWB}$ at its upstream edge. Because of its overturning features at its flanks, the Atlantic ridge could be identified as a block. This ridge can be interpreted as a precursor block. Gómara et al. (2014) found that cyclonic Rossby wave breaking over eastern Greenland leads to an acceleration of the jet stream over the North Atlantic being favorable for cyclogenesis in this region. We hypothesize that there is a linkage between the Atlantic ridge with $\mathrm{CWB}$ and the development or intensification of cyclones that may support the evolution of the EuroRussian block downstream. Moreover, the Atlantic precursor ridge coincided with high IVT values, and both were positively correlated to the metric (which describes the blocking ridge), indicating that there could be a dynamical relation. The high IVT values are related to the surface cyclone propagating along the U.S. East Coast toward Greenland. High IVT values are a proxy for ARs and WCBs and thus are likely associated with diabatic processes. The latter can influence wave amplification at upper levels via PV depletion or divergence (e.g., Teubler and Riemer 2016). ARs that hit the southern coast of Greenland especially have been identified to play an important role in block formation in the North Atlantic region (Schwierz 2001). As high IVT reaches the coast, it is forced to ascend (Ralph and Dettinger 2011; Lavers et al. 2012), resulting in condensation and precipitation. This release of latent heat leads to an upper-level PV depletion that strengthens the negative PV anomaly at the dynamical tropopause (Schwierz 2001). We hypothesize that the high IVT values west and south of Greenland had an effect on the predictability of the Russian heat wave block, as they influenced the Atlantic precursor block. As the occurrence of the precursor block is identified to be important for the evolution of the block over Europe, the IVT in the vicinity of Greenland is one of the key processes for the block's predictability. Moreover, the presence of an AR is related to cyclone activity (e.g., Neiman et al. 2008; Dacre et al. 2015; EirasBarca et al. 2018). As mentioned above, an upper-level trough associated with a surface cyclone was identified in vicinity of high IVT around $60^{\circ}-80^{\circ} \mathrm{W}$. Independent of the role of the AR, surface cyclones are known as key components during blocking formation, as they act as sources of PV and energy (Colucci 1985, 1987). The positive correlation to IVT over Europe suggests that diabatic processes play a key role in block formation in that location as well. Thus, the predictability of the block during its onset phase was influenced by cyclone/wave dynamics, partly associated with diabatic processes. The synoptic situation upstream of the block (Atlantic/Greenland) seems to be one of the key sources of forecast uncertainty. The synoptic evolution in individual members (with/without block's onset) is provided in Fig. S1 in the online supplemental material.

The sensitivities to Z500 and MSLP were more significant than the sensitivities to IVT. Significance here means spatial and temporal consistency of the sensitivity pattern. One reason for the differences between Z500 and IVT signals could be that the metrics are based on Z500. Correlations between IVT and Z500 can be expected to be weaker, since the variables are more independent. Another reason could be that relevant diabatic processes (indicated by the occurrence of areas of high IVT) occurred on smaller spatial scales.

To investigate the behavior of the single EPS in the ESA approach, we plotted values of the state variables at grid points with strong sensitivities (showing a high correlation to the metric). Different colors mark the origin of the members from the different EPSs. This should illustrate whether groupings of members of the same EPS can be identified. For the onset phase, the dependence from the EPS is shown in Fig. 5. For Z500, the NCEP members are partly separated from the UKMO members, indicating the occurrence of two clusters (Fig. 5a). However, the ECMWF members lie close to the members from the other EPSs, showing that the ECMWF ensemble is representative of the variability that is present in the multimodel ensemble. This is also visible in the means of the data points from the different EPSs, since the mean of the ECMWF members lies between the means of the UKMO and the NCEP members. For MSLP, the ECMWF and the NCEP means lie close together, while the UKMO mean is more separated (Fig. 5b). There seems to be two clusters (being not clearly separated), with ECMWF and NCEP members in the one cluster and UKMO members in the other cluster. However, some members of the ECMWF ensemble are distributed in the same range (metric values between 5600 and $5700 \mathrm{gpm}$ ) as some UKMO members. This is also true for IVT (Fig. 5c), as ECMWF and NCEP 
a) Z500 at $40^{\circ} \mathrm{W} / 75^{\circ} \mathrm{N}(0000$ UTC 19 Jun 2010)

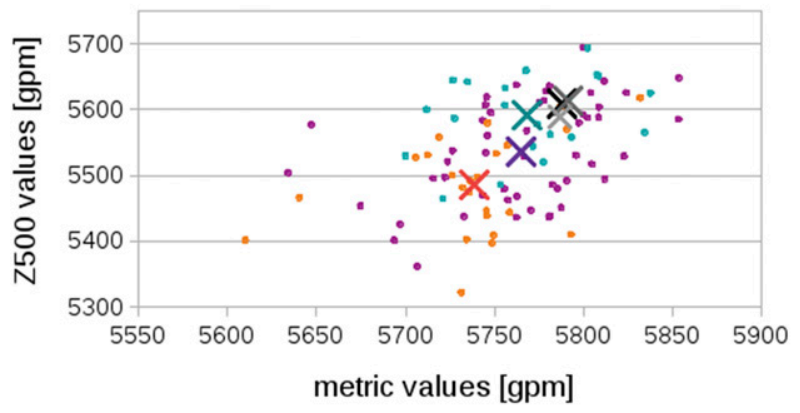

b) MSLP at $20^{\circ} \mathrm{W} / 75^{\circ} \mathrm{N}(0000$ UTC 19 Jun 2010)

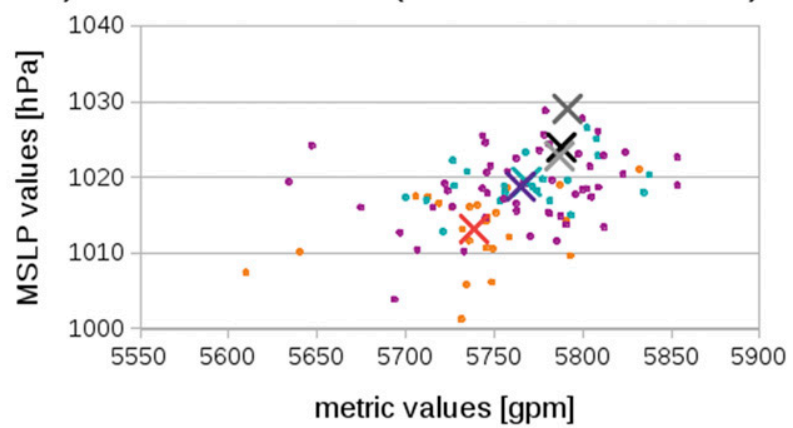

c) IVT at $60^{\circ} \mathrm{W} / 70^{\circ} \mathrm{N}(0000$ UTC 19 Jun 2010$)$

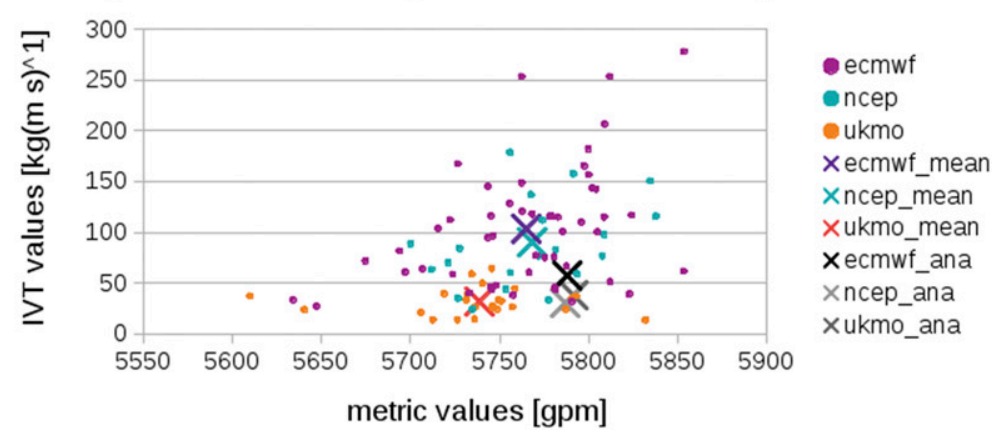

FIG. 5. Scatterplots for (a) the 500-hPa geopotential height (Z500) at $75^{\circ} \mathrm{N}, 40^{\circ} \mathrm{W}$; (b) the MSLP at $75^{\circ} \mathrm{N}, 20^{\circ} \mathrm{W}$; and (c) the IVT at $70^{\circ} \mathrm{N}$, $60^{\circ} \mathrm{W}$ on $19 \mathrm{Jun} 2010$. Values of the state variables at grid points with strong sensitivity signals ( $y$ axis) are plotted against the metric values ( $x$ axis). The dots illustrate the single ensemble members, while their color indicates the EPS origin. The colored crosses show the ensemble means, while the black and gray crosses belong to the three analysis members.

members are distributed more similarly, while the UKMO members are more separated. In conclusion, there seems to be some kind of clustering. Thus, the ESA results (being sensitive to the choice of EPSs) mirror in some way the differences between the EPSs. However, the areas covered by the members from different EPSs are not distinctly separated. Therefore, we conclude that the dependence of the results from the chosen EPSs is not negligible, but it is fair to say that the ESA signals do not only reflect the differences between the three EPSs.

\section{Mature stage of the block}

\section{a. Synoptic overview}

Figure 6 shows the wave pattern in the Z500 field upstream of the block and the blocking ridge itself for the mature stage in the analysis. On 26 July, the block is tilted northwestward, associated with an upstream southeast-tilted trough, implying CWB around $20^{\circ} \mathrm{E}$ (Fig. 6a). Over the Atlantic and the U.S. East Coast, two short-wave troughs are visible, and both are associated with surface cyclones. Such cyclones may influence the maintenance of the block (Frederiksen and Webster 1988), as they transport energy and PV to the block [cf. onset phase of the block; Colucci $(1985,1987)]$. The orientation of the block changes between 29 and 31 July to a northeast tilt (Figs. 6d-f), while the amplitude of the trough on the block's western flank decreases.

\section{b. Sensitivity results}

For the mature stage, the metric is calculated as differences between the average Z500 within two adjacent boxes (boxes A and B in Fig. 7a). Positive (negative) sensitivities show where an increase in the state variable corresponds to a trough upstream of the block, which is forecast farther east (west) or is forecast to undergo CWB (AWB).

On 30 July $(-24 \mathrm{~h})$, the sensitivity in the Z500 field is dominated by a positive sensitivity at $30^{\circ} \mathrm{W}$ and a negative sensitivity at $0^{\circ}$ along the flanks of the trough upstream of the blocking ridge, located around $40^{\circ} \mathrm{E}$ (Fig. 7a). The negative sensitivity is spatially extended in its zonal direction and reaches from $70^{\circ} \mathrm{N}, 60^{\circ} \mathrm{W}$ to $65^{\circ} \mathrm{N}$, $90^{\circ} \mathrm{E}$, with a maximum at $55^{\circ} \mathrm{N}, 5^{\circ} \mathrm{W}$. Furthermore, two positive sensitivities at $70^{\circ} \mathrm{W}$ (within a trough) and at $50^{\circ} \mathrm{E}$ (within the blocking ridge) are identified. 

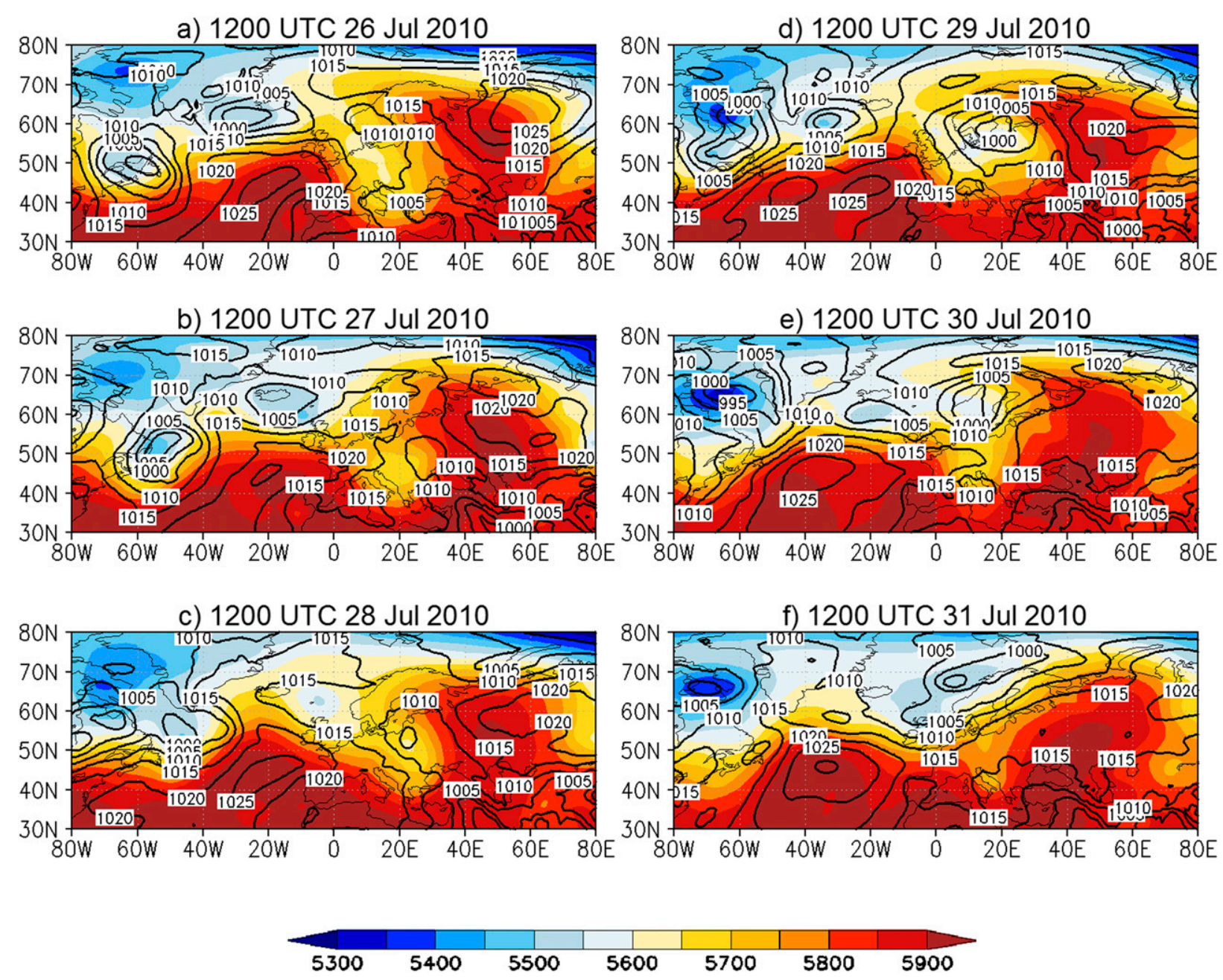

FIG. 6. As in Fig. 3, but from (a) 1200 UTC 26 Jul to (f) 1200 UTC 31 Jul 2010.

On 29 July $(-48 \mathrm{~h})$, the sensitivity dipole is farther west: the positive sensitivity is located farther south and stretched along a ridge-trough-ridge structure between $60^{\circ} \mathrm{W}$ and $0^{\circ}$, while the negative one is farther north (Fig. 7b).

The dipole of Z500 sensitivities over the Atlantic shows the correlation regarding the position of the trough upstream of the block at 30 July to its position at 31 July. The negative sensitivity of the dipole over the Atlantic is much more extended than the positive one and indicates that less amplified ridges upstream (over Greenland) and downstream (the blocking ridge) are associated with AWB or with a westward shift of the block's western flank on 31 July. This behavior or position of the block's western flank is associated with a stronger trough upstream at the U.S. East Coast.

The MSLP sensitivities are similar to the Z500 sensitivities (Figs. 7c,d). On 30 July ( $-24 \mathrm{~h}$ ), a sensitivity dipole is visible between $40^{\circ} \mathrm{W}$ and $40^{\circ} \mathrm{E}$ (Fig. $7 \mathrm{c}$ ). In addition, a weaker sensitivity dipole is present between $40^{\circ}$ and $80^{\circ} \mathrm{W}$ (Figs. $7 \mathrm{c}, \mathrm{d}$ ).

The positive sensitivity at $30^{\circ} \mathrm{W}$ shows the area where higher (lower) surface pressure is related to an eastward (westward) shifted western flank of the block. The negative sensitivity downstream shows the area where higher (lower) pressure is related to a westward (eastward) shift of the block's western flank. The sensitivities between $40^{\circ}$ and $80^{\circ} \mathrm{W}$ address the shift of a surface cyclone that is placed between Greenland and Canada. If the cyclone is located over Canada, then the block's western flank is located farther east. If the cyclone is located over Greenland, then the block's western flank is located farther west.

The strongest sensitivities to IVT on 30 July ( $-24 \mathrm{~h}$ ) are identified over the Atlantic and western Europe (Fig. 7e). Around $40^{\circ} \mathrm{W}$, a dipole with a northern positive and a southern negative sensitivity lies in an area of high IVT $\left[\sim 300 \mathrm{~kg}(\mathrm{~m} \mathrm{~s})^{-1}\right]$. Another positive sensitivity extends 
Z500

a) $-24 \mathrm{~h}$ (1200 UTC $30 \mathrm{Jul} 2010$ )

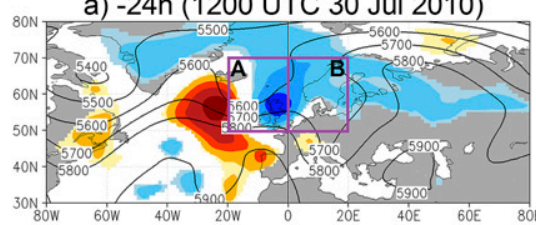

b) $-48 \mathrm{~h}(1200$ UTC $29 \mathrm{Jul} 2010)$

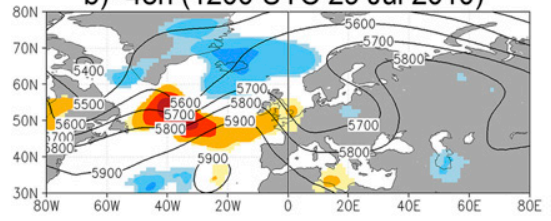

MSLP

c) $-24 \mathrm{~h}$ (1200 UTC 30 Jul 2010)

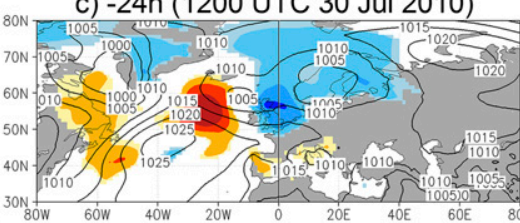

d) $-48 \mathrm{~h}(1200$ UTC 29 Jul 2010)

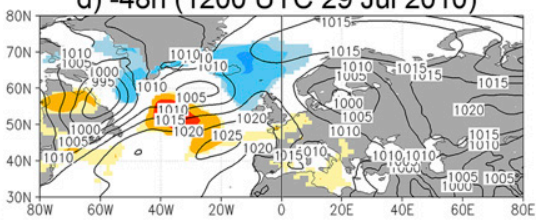

IVT

e) $-24 \mathrm{~h}$ (1200 UTC 30 Jul 2010)

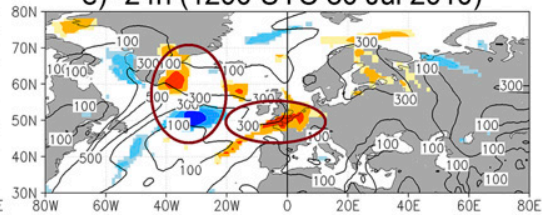

f) $-48 \mathrm{~h}$ (1200 UTC 29 Jul 2010)

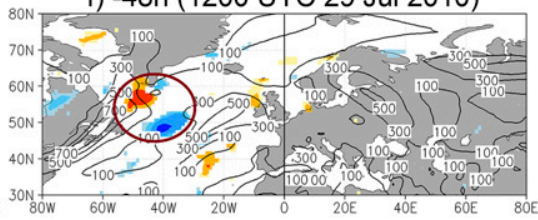

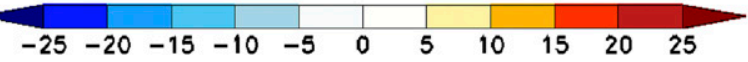

FIG. 7. Statistically significant sensitivities (shading in gpm) of the metric (difference of means of two adjacent boxes in 500-hPa geopotential height) at 1200 UTC 31 Jul 2010 (the metric time) to (a),(b) the 500-hPa geopotential height (Z500), (c),(d) the MSLP, and (e),(f) the IVT from $-24 \mathrm{~h}$ (1200 UTC $30 \mathrm{Jul} 2010)$ back to $-48 \mathrm{~h}$ (1200 UTC 29 Jul 2010) before metric time, plus the corresponding ensemble mean of Z500 (contours in gpm), of MSLP (contours in hPa), and of IVT [contours in $\mathrm{kg}(\mathrm{m} \mathrm{s})^{-1}$ ]. Purple boxes A and B in (a) show the area that was considered to calculate the metric. Brown circles highlight the IVT sensitivities that are discussed in the text.

from $55^{\circ} \mathrm{N}, 5^{\circ} \mathrm{E}$ to $40^{\circ} \mathrm{N}, 20^{\circ} \mathrm{W}$. The dipole over the Atlantic can be already found on 29 July ( -48 h; Fig. $7 f)$.

The dipole structure of the IVT sensitivities around $40^{\circ} \mathrm{W}$ indicates that a northwest shift of high IVT values is associated with CWB or an eastward shift of the block's western flank on 31 July. The same is true if higher IVT is present between $20^{\circ} \mathrm{W}$ and $0^{\circ}$, while lower IVT at this location is associated with AWB or a westward shift of the block's western flank.

In conclusion, the forecast variability of the block's western flank during the mature stage seems to be related to the forecast variability of the amplitude of the upstream and downstream midtropospheric wave pattern and surface pressure systems, as well as on the western flank itself at shorter lead times. Moreover, the prediction of the block's western flank seems to be connected with the IVT forecast over Europe and the Atlantic, especially toward the southern coast of Greenland.

\section{c. Discussion}

During the mature stage of the block, its western flank was characterized by low predictability (Figs. 1d-f). In some members, the block's flank was shifted eastward, while in others it was shifted westward. Even for the members that showed a tendency for wave breaking, the direction of breaking differed from member to member. This forecast variability of the block's western flank was correlated to the amplitude of the wave pattern over the Atlantic-European sector. A dependence of wave breaking on the wave's meridional amplitude has been documented by Nakamura and Plumb (1994): less amplified waves do not generally break, waves of moderate amplitude tend to break only toward the closer critical line (the region where the mean zonal winds change sign), and strongly amplified waves can break in both directions. In addition, the predictability of the block's western flank was also influenced by the occurrence of ARs (high IVT values) over Europe and near Greenland. As for the onset phase, the ARs might support the wave amplification via latent heat release (Schwierz 2001), and the presence of high IVT or ARs implies the presence of surface cyclones (e.g., Neiman et al. 2008). Short-wave upper-level troughs (associated with surface cyclones) could be observed over the Atlantic during the mature stage of the block. These cyclones might have influenced the upper-level flow divergence via latent heat release (as it was observed for tropical cyclones undergoing extratropical transition; Agustí-Panareda et al. 2004). The state of the upper-level flow leads to a preferred direction of wave breaking: a confluent flow favors equatorward AWB (LC1), while a diffluent flow favors equatorward CWB (LC2; Thorncroft et al. 1993; Gabriel and Peters 2008). Upper-level wave and surface cyclone dynamics, as well as associated diabatic processes, seem to have had an impact on the predictability of the block's western flank during its mature stage. The synoptic evolution in individual members (with different representation of the block's western flank) can be found in Fig. S2. 
a) Z500 at $40^{\circ} \mathrm{W} / 55^{\circ} \mathrm{N}(1200$ UTC $29 \mathrm{Jul} 2010)$

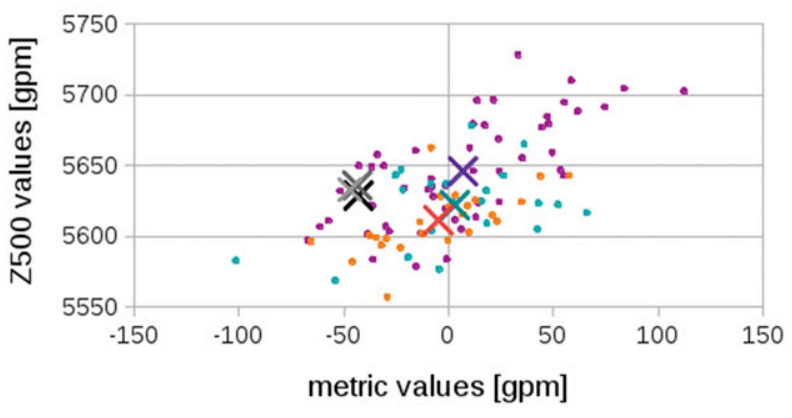

b) $\mathrm{MSLP}$ at $35^{\circ} \mathrm{W} / 55^{\circ} \mathrm{N}(1200 \mathrm{UTC} 29 \mathrm{Jul} 2010)$

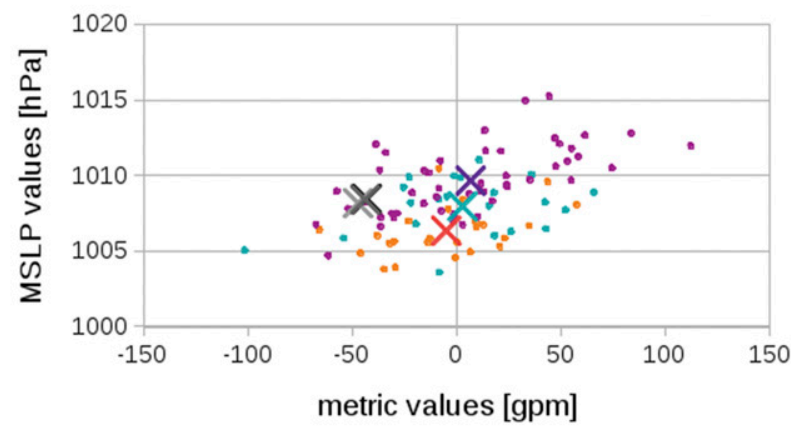

c) IVT at $45^{\circ} \mathrm{W} / 55^{\circ} \mathrm{N}(1200$ UTC 29 Jul 2010)

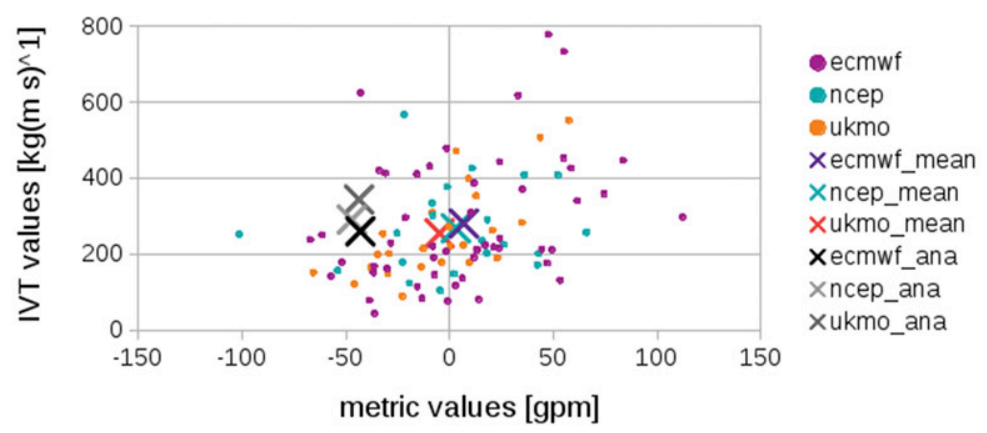

FIG. 8. As in Fig. 5, but for (a) Z500 at $55^{\circ} \mathrm{N}, 40^{\circ} \mathrm{W}$; (b) MSLP at $55^{\circ} \mathrm{N}, 35^{\circ} \mathrm{W}$; and (c) IVT at $55^{\circ} \mathrm{N}, 45^{\circ} \mathrm{W}$ on $29 \mathrm{Jul} 2010$.

For the mature stage, specific values of the state variables (within areas of high sensitivities) are plotted against metric values in Fig. 8. For all state variables (Z500, MSLP, and IVT), the EPS means lie close together. Thus, the members from the different EPSs are similarly distributed. In contrast to the onset phase, certain clusters cannot be observed. We conclude that the ESA signals are less sensitive to the choice of EPSs during the mature stage of the block than during the block's onset.

\section{Decay phase of the block}

\section{a. Synoptic overview}

In the analysis, a trough over Canada and Greenland, as well as a cutoff low around $0^{\circ}$, are present upstream of the block on 10 August 2010 (Fig. 9a). After 13 August, another trough over Canada propagates eastward with increasing amplitude (Figs. 9d-g). Again, the presence of arriving surface cyclones from upstream seems to influence blocking dynamics. On 15 and 16 August, there is a low-high dipole in surface pressure (coinciding with low-over-high Z500 values) between $20^{\circ}$ and $40^{\circ} \mathrm{W}$ upstream of the decaying block (Figs. 9f,g). During the weakening phase, the two ridges around $20^{\circ} \mathrm{W}$ and $40^{\circ} \mathrm{E}$ merge and encompass the cutoff low at $10^{\circ} \mathrm{E}$ (Figs. 9e-g). In addition, the surface low (coinciding with low Z500 values) northeast of the decaying block between $20^{\circ}$ and $80^{\circ} \mathrm{E}$ at $75^{\circ} \mathrm{N}$ deepens from 15 August onward (Fig. 9f).

\section{b. Sensitivity results}

For the decay phase of the block, positive (negative) sensitivities indicate where an increase in the state variable is associated with an increase (decrease) in the forecast of area-averaged $\mathrm{Z} 500$ between $35^{\circ} \mathrm{W}$ and $30^{\circ} \mathrm{E}$.

On 15 August $(-24 \mathrm{~h})$, a large positive Z500 sensitivity signal is identified around $0^{\circ}$, corresponding to the western half of the Euro-Russian summer block (Fig. 10a). Farther south, a negative sensitivity lies partly in the cutoff low between the two ridges belonging to the blocking system. An additional negative sensitivity signal is located within a trough over southern Greenland. Moreover, a positive sensitivity area is located within a ridge at the U.S. East Coast. Most of the sensitivities are already visible on 14 August ( $-48 \mathrm{~h}$; Fig. 10b) and on 13 August ( $-72 \mathrm{~h}$; Fig. 10c), but with smaller magnitudes than on 15 August ( -24 h; Fig. 10a).

Focusing on the strongest sensitivities, an amplified double ridge between $40^{\circ} \mathrm{W}$ and $60^{\circ} \mathrm{E}$ is associated with an amplified block on 16 August. An amplified block on 16 August is also associated with a deeper cutoff 

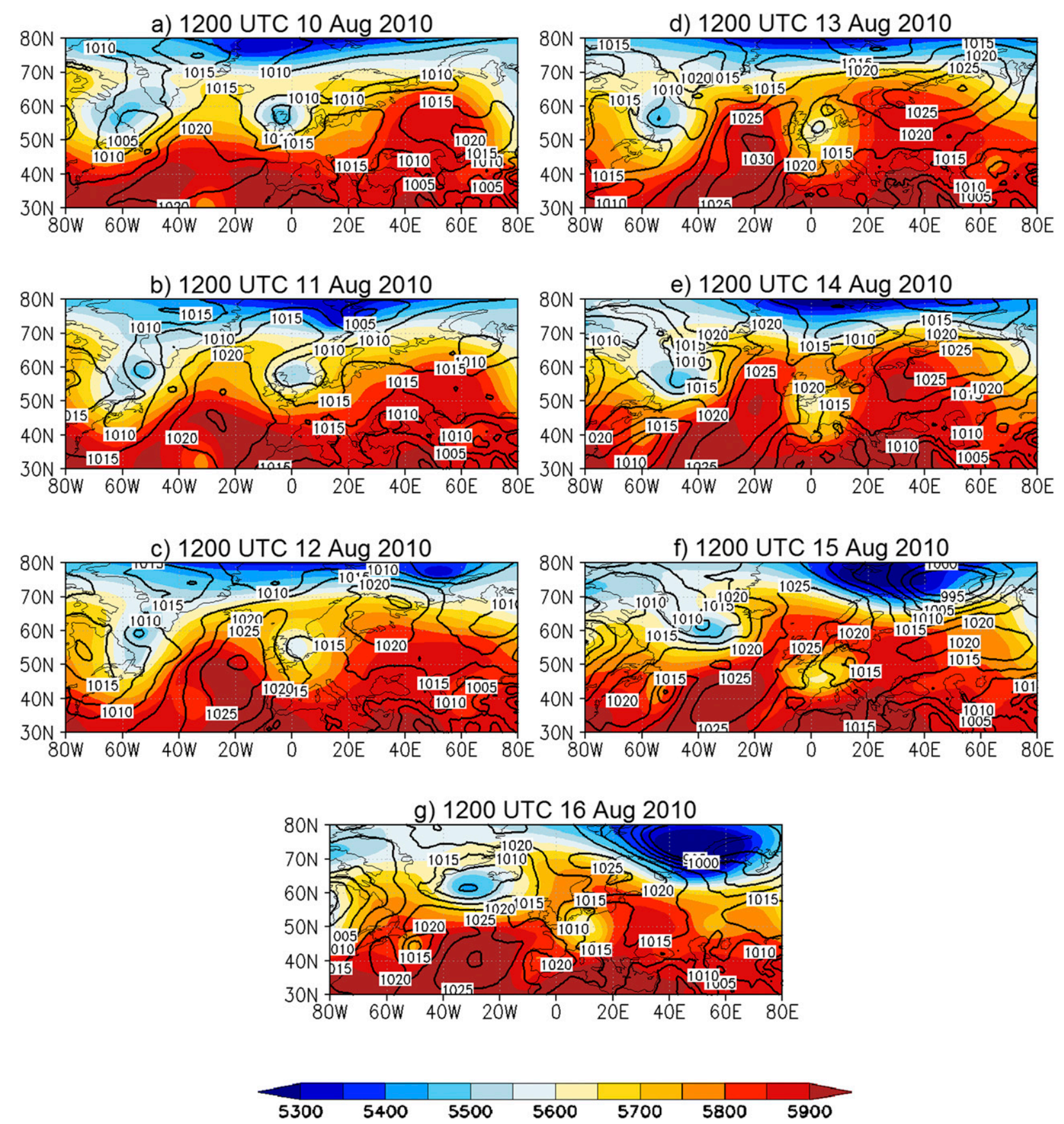

FIG. 9. As in Fig. 3, but from (a) 1200 UTC 10 Aug to (f) 1200 UTC 16 Aug 2010.

low at $0^{\circ}$, a deeper trough over Greenland, and a stronger ridge at the U.S. East Coast at shorter forecast lead times.

The sensitivities to MSLP are similar to those of Z500 (Figs. 10d-f). On 15 August $(-24 \mathrm{~h})$, a large positive sensitivity is centered at $60^{\circ} \mathrm{N}, 0^{\circ}$ (Fig. 10d). It can be traced back to 13 August ( $-72 \mathrm{~h}$; Fig. 10f). A weaker negative sensitivity is located south of the positive sensitivity (Fig. 10d). Moreover, a positive sensitivity can be found at the U.S. East Coast (Figs. 10d-f).

Thus, an amplified blocking ridge on 16 August is associated with an intensified high pressure system at $60^{\circ} \mathrm{N}$ and a deeper low pressure system at $40^{\circ} \mathrm{N}$ (between $40^{\circ} \mathrm{W}$ and $20^{\circ} \mathrm{E}$ ) at shorter lead times. The positive signal at the U.S. East Coast indicates an area where higher pressure is associated with an amplified blocking ridge downstream. 
Z500

a) $-24 \mathrm{~h}$ (1200 UTC 15 Aug 2010)

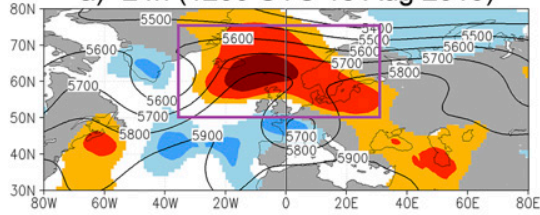

b) $-48 \mathrm{~h}$ (1200 UTC 14 Aug 2010)

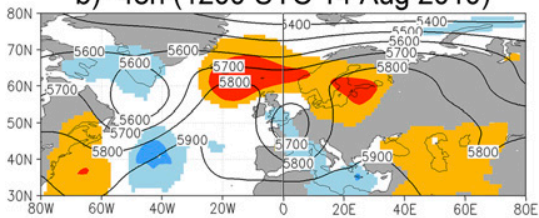

c) $-72 \mathrm{~h}$ (1200 UTC 13 Aug 2010)

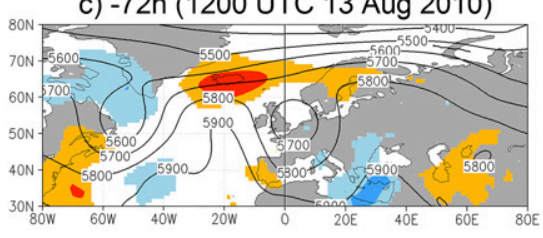

MSLP

d) -24 h (1200 UTC 15 Aug 2010)

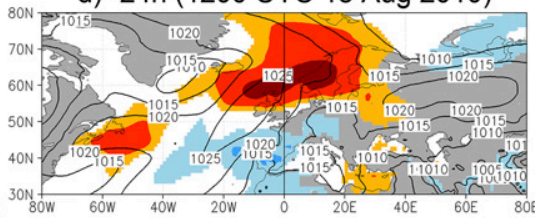

e) $-48 \mathrm{~h}$ (1200 UTC 14 Aug 2010)

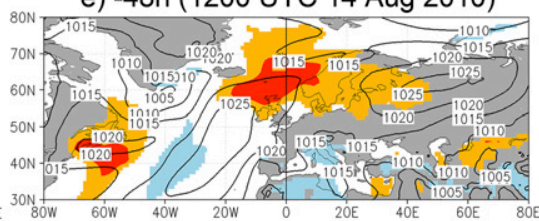

f) $-72 \mathrm{~h}$ (1200 UTC 13 Aug 2010)

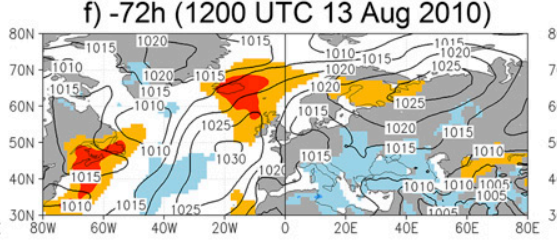

IVT

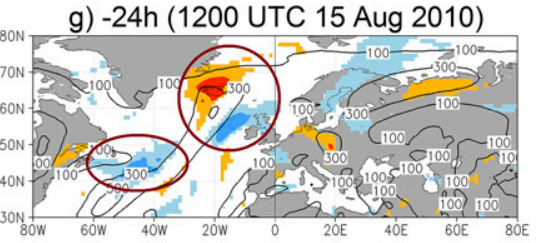

h) $-48 \mathrm{~h}$ (1200 UTC 14 Aug 2010)

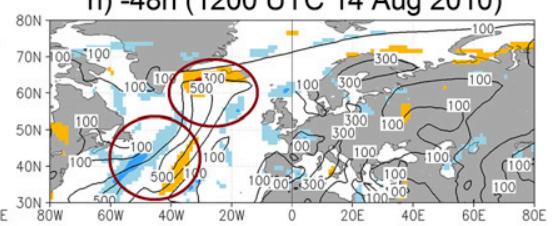

i) -72h (1200 UTC 13 Aug 2010)
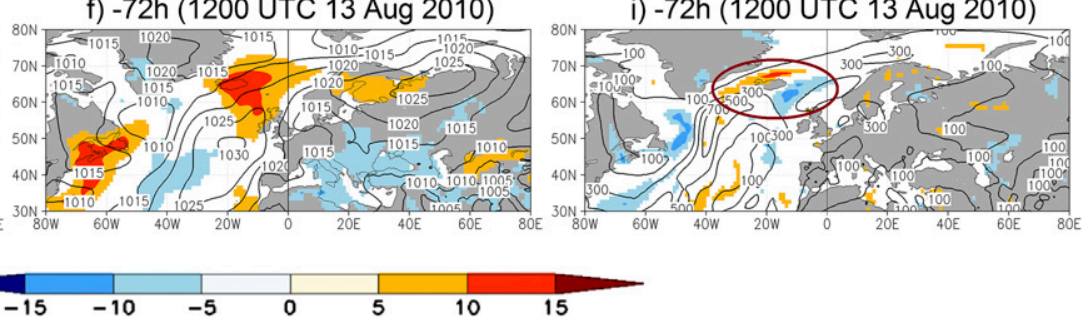

FIG. 10. Statistically significant sensitivities (shading in gpm) of the metric (box mean in 500-hPa geopotential height) at 1200 UTC 16 Aug 2010 (the metric time) to (a)-(c) the 500-hPa geopotential height (Z500), (d)-(f) the MSLP, and (g)-(i) the IVT from -24 h (1200 UTC15 Aug 2010) back to $-72 \mathrm{~h}$ (1200 UTC 13 Aug 2010) before metric time, plus the corresponding ensemble mean of Z500 (contours in gpm), of MSLP (contours in $\mathrm{hPa}$ ), and of IVT [contours in $\mathrm{kg}(\mathrm{m} \mathrm{s})^{-1}$ ]. Purple box in (a) shows the area that was considered to calculate the metric. Brown circles highlight the IVT sensitivities that are discussed in the text. Please note that the color bar is different than those in Fig. 4 and Fig. 7.

On 15 August $(-24 \mathrm{~h})$, the strongest sensitivities to IVT are present between Greenland and Great Britain, where high values of IVT are visible (Fig. 10g). These sensitivities appear as a dipole with a southern negative and a northern positive sensitivity, which is less intense on 13 August ( -72 h; Fig. 10i). Another weaker sensitivity dipole is located between $40^{\circ}$ and $60^{\circ} \mathrm{W}$ around $45^{\circ} \mathrm{N}$ (Fig. 10g). These sensitivities are more extended in their meridional direction on 14 August ( $-48 \mathrm{~h}$; Fig. 10h) than on 15 August ( $-24 \mathrm{~h}$; Fig. $10 \mathrm{~g}$ ). The sensitivity pattern for IVT over Europe is generally spotty (Figs. $10 \mathrm{~g}-\mathrm{i}$ ).

Thus, the most coherent pattern of sensitivities to IVT is found over the Atlantic. Since the sensitivities appear as dipoles along an area of high IVT in the ensemble mean, they indicate that a shift of high IVT to the west around $60^{\circ} \mathrm{N}$ and to the east around $40^{\circ} \mathrm{N}$ (corresponding to a more meridional orientation of high IVT) is associated with an amplified blocking ridge on 16 August.

In conclusion, the forecast variability of the block during its decay phase seems to be related to the predictability of wave structures and IVT dynamics (indicating diabatic processes) at shorter lead times. Toward the metric time (16 August), a dipole of sensitivities to Z500 is visible, similar to a high-over-low pattern described as a Rex block (Rex 1950). In addition, the forecast of the ridge-trough couplet around $60^{\circ} \mathrm{W}$ seems to be relevant for the prediction of the block downstream. Moreover, the forecast variability of the Atlantic high IVT (with a strong meridional component) may also play an important role for the forecast at longer lead times.

\section{c. Discussion}

During the decay phase of the block, some members predicted the decay correctly, while others did not (Figs. 1g-i). The forecast variability of the block was correlated to uncertainties in the prediction of upstream troughs associated with surface cyclones. Short-wave troughs/cyclones influence blocks via, for example, advection of low-PV air from lower latitudes along the eastern flank of the troughs/cyclones into the blocked area, being itself a negative PV anomaly (Crum and Stevens 1988). This influence depends on the phasing between the cyclone and the block and on the persistence of the forcing in space and time (Colucci 1985; Frederiksen and Webster 1988; Michel et al. 2012). Again, upstream cyclones along the U.S. East Coast could be observed together with high IVT over the 
a) Z500 at $10^{\circ} \mathrm{W} / 75^{\circ} \mathrm{N}(1200$ UTC 14 Aug 2010)

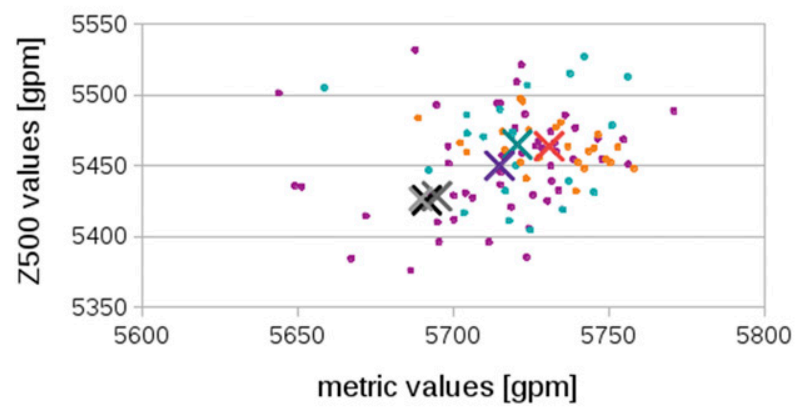

b) MSLP at $0^{\circ} / 75^{\circ} \mathrm{N}(1200$ UTC 14 Aug 2010)

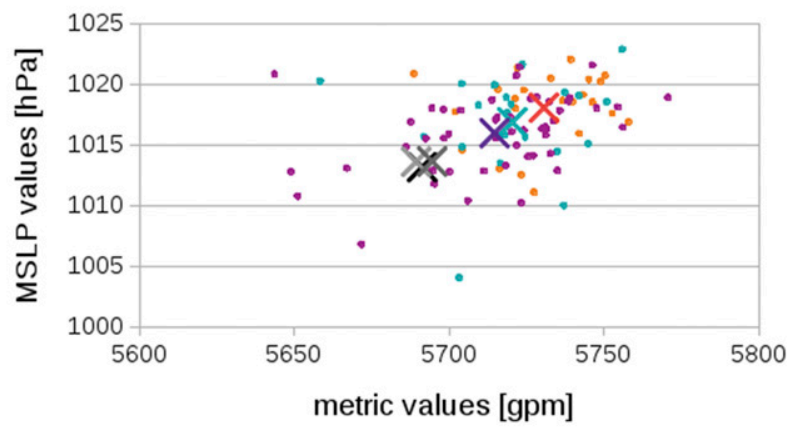

c) IVT at $35^{\circ} \mathrm{W} / 62^{\circ} \mathrm{N}$ (1200 UTC 14 Aug 2010)

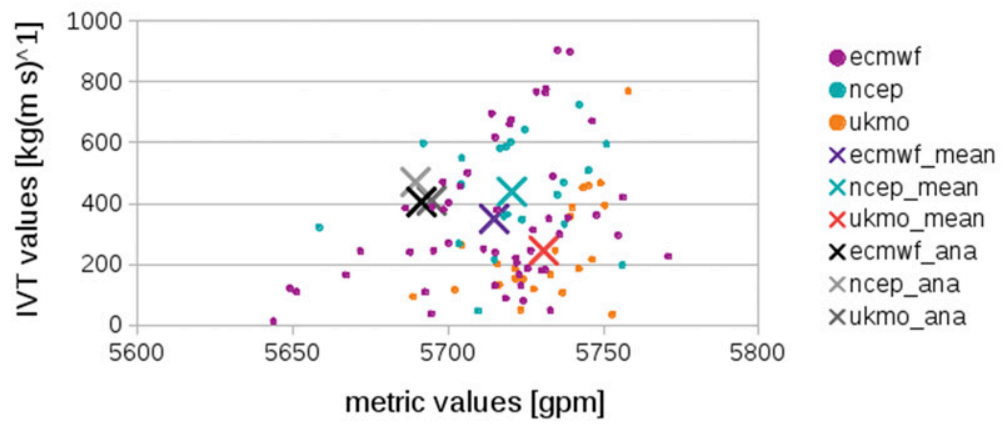

FIG. 11. As in Fig. 5, but for (a) Z500 at $75^{\circ} \mathrm{N}, 10^{\circ} \mathrm{W}$; (b) MSLP at $75^{\circ} \mathrm{N}, 0^{\circ}$; and (c) IVT at $62^{\circ} \mathrm{N}, 35^{\circ} \mathrm{W}$ on 14 Aug 2010.

Atlantic, indicating the presence of an AR. However, strong MSLP sensitivities in the vicinity of surface cyclones upstream of the block could not be observed. An AR with a strong meridional component was correlated to the suppression of the block's decay, maybe as this AR contributed to wave amplification via latent heat release (Schwierz 2001). The forecast variability of the cutoff low south of the positive Z500 anomaly associated with the block itself seemed to play a crucial role for predictability. The strengthening of the cutoff low might have indicated the transformation of the omega-shaped block to a high-over-low block (Rex 1950). Thus, the predictability of the block's decay was dependent on uncertainties in the transformation of the blocking pattern. Moreover, the forecast variability of the block's decay depended to a lesser extent on upstream cyclones and to a greater extent on associated diabatic processes. The synoptic evolution in individual members (with/without block's decay) is shown in Fig. S3.

The ESA signals for the decay period were less intense than for the other life cycle phases of the block. This could result from the choice of the metric or of state variables or from a lower forecast uncertainty in general. Although the signals are weaker for this phase, they are still statistically significant.
The relation between values of the three investigated state variables and the metric values for the decay phase of the block is shown in Fig. 11. For Z500, UKMO members are more localized than ECWMF and NCEP members (Fig. 11a). Thus, the ECMWF and the NCEP ensembles represent a larger forecast variability. This is also true for the other two state variables (Figs. 11b,c). In addition, the ensemble means are placed at different positions (especially for IVT), indicating EPS clusters. Thus, to a certain degree, the ESA signals mirror the differences among the three EPSs. Since the clusters are not clearly separated from each other, we come to the same conclusions as for the onset phase of the block: namely, the ESA signals are not only the result of members originating from the same EPS.

\section{Summary and conclusions}

The objective of this study was to identify features in the synoptic development of the Euro-Russian 2010 summer block that limited its predictability during three significant life cycle phases, namely, its onset, mature, and decay phases. We used three medium-range TIGGE ensemble forecasts following Q17 and performed an ESA. The successful application of ESA to investigate atmospheric 
blocking was already shown by Magnusson (2017) and Parker et al. (2018). The main conclusions are as follows:

- Which uncertainties in the synoptic-scale flow pattern were associated with uncertainties in the structure of the 2010 summer block?

Forecast uncertainties in the upper-level wave pattern (related to uncertainties in the surface pressure) as well as in IVT influenced the predictability of the block. These uncertainties address spatial shifts as well as the amplitude/intensity of synoptic waves and of IVT.

- Can the uncertainties associated with the block's predictability be related to dynamical processes?

The uncertainties in the upper-level wave pattern are related to wave dynamics including wave propagation, amplification, and breaking of waves. Upper-level troughs and the associated surface cyclones are important in two ways. On the one hand, they can support a block as they ensure the advection of low-PV air from lower latitudes into the block. On the other hand, surface cyclones are related to WCBs and ARs (IVT is used as a proxy) that can be associated with diabatic processes (latent heat release). These diabatic processes may enhance upperlevel wave amplification.

- Are the results associated with the block's forecast variability different among the three phases of the block's life cycle?

Both uncertainties in wave dynamics and diabatic processes were important for the predictability during the whole life cycle. During onset, the block's forecast variability was correlated with forecast uncertainties regarding a precursor block that evolved over the Atlantic. During the mature stage, the blocking ridge itself was highly predictable, while forecast uncertainties in the wave pattern and in IVT primarily influenced the block's western flank. For the decay phase, the transformation from an omega-shaped block to a high-overlow pattern was one of the key sources of uncertainty.

Addressing the influence of the forecast variability of (marine) cyclones on blocking prediction, our results agree with findings from earlier studies (Colucci 1985; Frederiksen et al. 2004). Parker et al. (2018) applied ESA on 15-day ECMWF ensemble forecasts to identify precursors in Z500 and Z50 (50-hPa geopotential height field) for high-latitude Greenland blocks. They found precursors at both levels, while the strongest one was a Rossby wave precursor reaching from the Pacific basin across North America. With regard to diabatic processes, we hypothesized that latent heat release was relevant as it modified the upper-level wave pattern. This effect on blocking predictability was described before by Tracton (1990). Another example for the relevance of the accurate representation of diabatic processes is the forecast bust in March 2016. The low predictability was related to a misforecast of a block and associated with forecast errors in WCB activity near Newfoundland that had a strong impact on the predictability in downstream regions (Grams et al. 2018).

We showed that the ESA approach can be used to investigate the forecast variability of the 2010 summer block and with multimodel ensembles. As this study only deals with a summer block, further studies could investigate the forecast variability of high-impact winter blocks that are related to cold waves. Moreover, since blocks are long-lasting phenomena, it would be also important to investigate their predictability in subseasonal to seasonal forecasts, as was recently done by Ferranti et al. (2018).

Acknowledgments. We thank the reviewers and the editor for valuable comments that helped to improve the structure and clarity of the paper. This study is part of LAQ's Ph.D. thesis conducted within and supported by the research group PANDOWAE (FOR896), funded by the German Research Council (DFG) as contribution to the WMO World Weather Research Programme THORPEX. This work is based on TIGGE data. TIGGE is an initiative of the World Weather Research Programme. We are grateful to D. Anwender for the initiation of the project. OM acknowledges funding by the Swiss National Science Foundation Project 200021-137543. JGP thanks the AXA Research fund for support.

\section{APPENDIX}

\section{Selection of EPS and Ensemble Forecasts}

Since we build on the findings from Q17, the same ensemble forecasts are used. The following remarks are a summary of the detailed description given in Q17 (sections $2 \mathrm{a}$ and $2 \mathrm{~b}$ therein).

TIGGE contains 10 EPSs, from which three were chosen. The ECMWF, NCEP, and UKMO provide the 2-PVU (1 PVU $=10^{-6} \mathrm{~K} \mathrm{~kg}^{-1} \mathrm{~m}^{2} \mathrm{~s}^{-1}$ ) potential temperature, which was required for the calculation of the blocking index.

The onset date of the block was identified as 20 June, and 17 August was the decay date (Q17). Thus, forecasts initialized before the respective dates were used to assess the predictability of the block's onset and decay, respectively. For the mature stage, a large forecast variability of the block's western flank was found for the end of July (M11). Therefore, several forecast starting dates could have been used for the investigation of the forecast variability. In Q17, we compared the ensemble spread of several forecasts with the help of spaghetti plots (showing the 5600 gpm isolines) and Hovmöller plots (showing the ensemble spread in Z500) to make a further subselection. Finally, we chose 
forecasts with a large ensemble spread, as we wanted forecasts with and without the block's onset and decay, respectively, as well as with a different representation of the block's western flank during the mature stage of the block.

\section{REFERENCES}

Agustí-Panareda, A., C. Thorncroft, G. Craig, and S. Gray, 2004: The extratropical transition of Hurricane Irene (1999): A potential-vorticity perspective. Quart. J. Roy. Meteor. Soc., 130, 1047-1074, https://doi.org/10.1256/qj.02.140.

Arakawa, H., 1952: Kinematics of meandering and blocking action of the westerlies. Pap. Meteor. Geophys., 3, 12-18, https://doi.org/ 10.2467/mripapers1950.3.1_12.

Barriopedro, D., E. M. Fischer, J. Luterbacher, R. M. Trigo, and R. García-Herrera, 2011: The hot summer of 2010: Redrawing the temperature record map of Europe. Science, 332, 220-224, https://doi.org/10.1126/science.1201224.

Berggren, R., B. Bolin, and C.-G. Rossby, 1949: An aerological study of zonal motion, its perturbations and break-down. Tellus, 1, 14-37, https://doi.org/10.3402/tellusa.v1i2.8501.

Buehler, T., C. C. Raible, and T. F. Stocker, 2011: The relationship of winter season North Atlantic blocking frequencies to extreme cold or dry spells in the ERA-40. Tellus, 63A , 174-187, https://doi.org/10.1111/j.1600-0870.2010.00492.x.

Carrera, M., R. Higgins, and V. Kousky, 2004: Downstream weather impacts associated with atmospheric blocking over the northeast Pacific. J. Climate, 17, 4823-4839, https://doi.org/10.1175/ JCLI-3237.1.

Chang, E. K., M. Zheng, and K. Raeder, 2013: Medium-range ensemble sensitivity analysis of two extreme Pacific extratropical cyclones. Mon. Wea. Rev., 141, 211-231, https://doi.org/10.1175/ MWR-D-11-00304.1.

Colucci, S. J., 1985: Explosive cyclogenesis and large-scale circulation changes: Implications for atmospheric blocking. J. Atmos. Sci., 42, 2701-2717, https://doi.org/10.1175/1520-0469(1985) 042<2701:ECALSC > 2.0.CO;2.

, 1987: Comparative diagnosis of blocking versus nonblocking planetary-scale circulation changes during synoptic-scale cyclogenesis. J. Atmos. Sci., 44, 124-139, https://doi.org/10.1175/ 1520-0469(1987)044<0124:CDOBVN >2.0.CO;2.

Croci-Maspoli, M., C. Schwierz, and H. Davies, 2007: A multifaceted climatology of atmospheric blocking and its recent linear trend. J. Climate, 20, 633-649, https://doi.org/ 10.1175/JCLI4029.1.

Crum, F. X., and D. F. Stevens, 1988: A case study of atmospheric blocking using isentropic analysis. Mon. Wea. Rev., 116, 223-241, https://doi.org/10.1175/1520-0493(1988)116<0223: $\mathrm{ACSOAB}>2.0 . \mathrm{CO} ; 2$.

Dacre, H. F., P. A. Clark, O. Martinez-Alvarado, M. A. Stringer, and D. A. Lavers, 2015: How do atmospheric rivers form? Bull. Amer. Meteor. Soc., 96, 1243-1255, https://doi.org/10.1175/ BAMS-D-14-00031.1.

Dettinger, M., F. Ralph, and D. Lavers, 2015: Setting the stage for a global science of atmospheric rivers. Eos, Trans. Amer. Geophys. Union, 96, https://doi.org/10.1029/2015EO038675.

Dole, R., and Coauthors, 2011: Was there a basis for anticipating the 2010 Russian heat wave? Geophys. Res. Lett., 38, L06702, https://doi.org/10.1029/2010GL046582.

Eiras-Barca, J., A. M. Ramos, J. G. Pinto, R. M. Trigo, M. L. Liberato, and G. Miguez-Macho, 2018: The concurrence of atmospheric rivers and explosive cyclogenesis in the North
Atlantic and North Pacific basins. Earth Syst. Dyn., 9, 91-102, https://doi.org/10.5194/esd-9-91-2018.

Ferranti, L., L. Magnusson, F. Vitart, and D. S. Richardson, 2018 How far in advance can we predict changes in large-scale flow leading to severe cold conditions over Europe? Quart. J. Roy. Meteor. Soc., 144, 1788-1802, https://doi.org/10.1002/qj.3341.

Frederiksen, J. S., and P. J. Webster, 1988: Alternative theories of atmospheric teleconnections and low-frequency fluctuations. Rev. Geophys., 26, 459-494, https://doi.org/10.1029/ RG026i003p00459.

- M. A. Collier, and A. B. Watkins, 2004: Ensemble prediction of blocking regime transitions. Tellus, 56A, 485-500, https:// doi.org/10.1111/j.1600-0870.2004.00075.x.

Gabriel, A., and D. Peters, 2008: A diagnostic study of different types of Rossby wave breaking events in the northern extratropics. J. Meteor. Soc. Japan, 86, 613-631, https://doi.org/ $10.2151 / \mathrm{jmsj} .86 .613$

Gómara, I., J. G. Pinto, T. Woollings, G. Masato, P. Zurita-Gotor, and B. Rodríguez-Fonseca, 2014: Rossby wave-breaking analysis of explosive cyclones in the Euro-Atlantic sector. Quart. J. Roy. Meteor. Soc., 140, 738-753, https://doi.org/10.1002/qi.2190.

Grams, C. M., H. Binder, S. Pfahl, N. Piaget, and H. Wernli, 2014 Atmospheric processes triggering the central European floods in June 2013. Nat. Hazards Earth Syst. Sci., 14, 1691-1702, https://doi.org/10.5194/nhess-14-1691-2014.

_- L. Magnusson, and E. Madonna, 2018: An atmospheric dynamics perspective on the amplification and propagation of forecast error in numerical weather prediction models: A case study. Quart. J. Roy. Meteor. Soc., 144, 2577-2591, https:// doi.org/10.1002/qj.3353.

Green, J., 1977: The weather during July 1976: Some dynamical considerations of the drought. Weather, 32, 120-126, https:// doi.org/10.1002/j.1477-8696.1977.tb04532.x.

Hong, C.-C., H.-H. Hsu, N.-H. Lin, and H. Chiu, 2011: Roles of European blocking and tropical-extratropical interaction in the 2010 Pakistan flooding. Geophys. Res. Lett., 38, L13806, https://doi.org/10.1029/2011GL047583.

Hoskins, B. J., and P. D. Sardeshmukh, 1987: A diagnostic study of the dynamics of the Northern Hemisphere winter of 1985-86. Quart. J. Roy. Meteor. Soc., 113, 759-778, https://doi.org/ 10.1002/qj.49711347705.

Houze, R., Jr., K. Rasmussen, S. Medina, S. Brodzik, and U. Romatschke, 2011: Anomalous atmospheric events leading to the summer 2010 floods in Pakistan. Bull. Amer. Meteor. Soc., 92, 291-298, https://doi.org/10.1175/2010BAMS3173.1.

Keller, J. H., 2017: Amplification of the downstream wave train during extratropical transition: Sensitivity studies. Mon. Wea. Rev., 145, 1529-1548, https://doi.org/10.1175/MWR-D-16-0193.1.

Lau, W. K., and K.-M. Kim, 2012: The 2010 Pakistan flood and Russian heat wave: Teleconnection of hydrometeorological extremes. J. Hydrometeor., 13, 392-403, https://doi.org/ 10.1175/JHM-D-11-016.1.

Lavers, D. A., G. Villarini, R. P. Allan, E. F. Wood, and A. J. Wade, 2012: The detection of atmospheric rivers in atmospheric reanalyses and their links to British winter floods and the large-scale climatic circulation. J. Geophys. Res., 117, D20106, https://doi.org/10.1029/2012JD018027.

Lejenäs, H., 1977: On the breakdown of the westerlies. Atmosphere, 15, 89-113, https://doi.org/10.1080/00046973.1977.9648433.

Liu, Q., 1994: On the definition and persistence of blocking. Tellus, 46, 286-298, https://doi.org/10.3402/tellusa.v46i3.15479.

Lupo, A. R., I. Mokhov, S. Dostoglou, A. Kunz, and J. Burkhardt, 2007: Assessment of the impact of the planetary scale on the 
decay of blocking and the use of phase diagrams and enstrophy as a diagnostic. Izv. Atmos. Ocean. Phys., 43, 45-51, https:// doi.org/10.1134/S0001433807010057.

- - M. G. Akperov, A. V. Chernokulsky, and H. Athar, 2012: A dynamic analysis of the role of the planetary- and synoptic-scale in the summer of 2010 blocking episodes over the European part of Russia. Adv. Meteor., 2012, 584257, https://doi.org/10.1155/2012/584257.

Magnusson, L., 2017: Diagnostic methods for understanding the origin of forecast errors. Quart. J. Roy. Meteor. Soc., 143, 2129-2142, https://doi.org/10.1002/qj.3072.

Martius, O., and Coauthors, 2013: The role of upper-level dynamics and surface processes for the Pakistan flood of July 2010. Quart. J. Roy. Meteor. Soc., 139, 1780-1797, https://doi.org/10.1002/qj.2082.

Matsueda, M., 2009: Blocking predictability in operational mediumrange ensemble forecasts. SOLA, 5, 113-116, https://doi.org/ 10.2151/sola.2009-029.

_ 2011: Predictability of Euro-Russian blocking in summer of 2010. Geophys. Res. Lett., 38, L06801, https://doi.org/10.1029/ 2010 GL046557.

Michel, C., G. Rivière, L. Terray, and B. Joly, 2012: The dynamical link between surface cyclones, upper-tropospheric Rossby wave breaking and the life cycle of the Scandinavian blocking. Geophys. Res. Lett., 39, L10806, https://doi.org/10.1029/ 2012 GL051682.

Mullen, S. L., 1987: Transient eddy forcing of blocking flows. J. Atmos. Sci., 44, 3-22, https://doi.org/10.1175/1520-0469(1987) 044<0003:TEFOBF $>2.0 . \mathrm{CO} ; 2$.

Nakamura, M., and R. A. Plumb, 1994: The effects of flow asymmetry on the direction of Rossby wave breaking. J. Atmos. Sci., 51, 2031-2045, https://doi.org/10.1175/1520-0469(1994) 051<2031:TEOFAO >2.0.CO;2.

Neiman, P. J., F. M. Ralph, G. A. Wick, J. D. Lundquist, and M. D. Dettinger, 2008: Meteorological characteristics and overland precipitation impacts of atmospheric rivers affecting the west coast of North America based on eight years of SSM/I satellite observations. J. Hydrometeor., 9, 22-47, https://doi.org/10.1175/ 2007JHM855.1.

Parker, T., T. Woollings, and A. Weisheimer, 2018: Ensemble sensitivity analysis of Greenland blocking in medium-range forecasts. Quart. J. Roy. Meteor. Soc., 144, 2358-2379, https:// doi.org/10.1002/qj.3391.

Pelly, J. L., and B. J. Hoskins, 2003a: How well does the ECMWF Ensemble Prediction System predict blocking? Quart. J. Roy. Meteor. Soc., 129, 1683-1702, https://doi.org/10.1256/ qj.01.173.

_ Sci., 60, 743-755, https://doi.org/10.1175/1520-0469(2003) $060<0743$ :ANPOB $>2.0 . \mathrm{CO} ; 2$.

Pfahl, S., C. Schwierz, M. Croci-Maspoli, C. M. Grams, and H. Wernli, 2015: Importance of latent heat release in ascending air streams for atmospheric blocking. Nat. Geosci., 8, 610-614, https://doi.org/10.1038/ngeo2487.

Quandt, L.-A., J. H. Keller, O. Martius, and S. C. Jones, 2017: Forecast variability of the blocking system over Russia in summer 2010 and its impact on surface conditions. Wea. Forecasting, 32, 61-82, https://doi.org/10.1175/WAF-D-16-0065.1.

Ralph, F., and M. Dettinger, 2011: Storms, floods, and the science of atmospheric rivers. Eos, Trans. Amer. Geophys. Union, 92, 265-266, https://doi.org/10.1029/2011EO320001.
Rex, D. F., 1950: Blocking action in the middle troposphere and its effect upon regional climate. Tellus, 2, 196-211, https://doi.org/ 10.1111/j.2153-3490.1950.tb00331.x.

Schneidereit, A., S. Schubert, P. Vargin, F. Lunkeit, X. Zhu, D. H. Peters, and K. Fraedrich, 2012: Large-scale flow and the longlasting blocking high over Russia: Summer 2010. Mon. Wea. Rev., 140, 2967-2981, https://doi.org/10.1175/MWR-D-11-00249.1.

Schumacher, R. S., 2011: Ensemble-based analysis of factors leading to the development of a multiday warm-season heavy rain event. Mon. Wea. Rev., 139, 3016-3035, https://doi.org/ 10.1175/MWR-D-10-05022.1.

Schwierz, C. B., 2001: Interactions of Greenland-scale orography and extra-tropical synoptic-scale flow. Ph.D. thesis, Swiss Federal Institute of Technology, 49 pp., https://doi.org/ 10.3929/ethz-a-004325718.

Shutts, G., 1983: The propagation of eddies in diffluent jetstreams: Eddy vorticity forcing of 'blocking' flow fields. Quart. J. Roy. Meteor. Soc., 109, 737-761, https://doi.org/10.1002/qj.49710946204.

Swinbank, R., and Coauthors, 2016: The TIGGE project and its achievements. Bull. Amer. Meteor. Soc., 97, 49-67, https:// doi.org/10.1175/BAMS-D-13-00191.1.

Tanaka, H., 1998: Numerical simulation of a life-cycle of atmospheric blocking and the analysis of potential vorticity using a simple barotropic model. J. Meteor. Soc. Japan, 76, 983-1008, https://doi.org/10.2151/jmsj1965.76.6_983.

Teubler, F., and M. Riemer, 2016: Dynamics of Rossby wave packets in a quantitative potential vorticity-potential temperature framework. J. Atmos. Sci., 73, 1063-1081, https://doi.org/ 10.1175/JAS-D-15-0162.1.

Thorncroft, C., B. Hoskins, and M. McIntyre, 1993: Two paradigms of baroclinic-wave life-cycle behaviour. Quart. J. Roy. Meteor. Soc., 119, 17-55, https://doi.org/10.1002/qj.49711950903.

Tibaldi, S., and F. Molteni, 1990: On the operational predictability of blocking. Tellus, 42A, 343-365, https://doi.org/10.3402/ tellusa.v42i3.11882.

Torn, R. D., 2010a: Diagnosis of the downstream ridging associated with extratropical transition using short-term ensemble forecasts. J. Atmos. Sci., 67, 817-833, https://doi.org/10.1175/2009JAS3093.1.

_ 2010b: Ensemble-based sensitivity analysis applied to African easterly waves. Wea. Forecasting, 25, 61-78, https:// doi.org/10.1175/2009WAF2222255.1.

_ Mon. Wea. Rev., 136, 663-677, https://doi.org/10.1175/ 2007MWR2132.1.

Tracton, M. S., 1990: Predictability and its relationship to scale interaction processes in blocking. Mon. Wea. Rev., 118, 16661695, https://doi.org/10.1175/1520-0493(1990)118<1666: PAIRTS $>2.0 . \mathrm{CO} ; 2$.

Trenberth, K. E., and J. T. Fasullo, 2012: Climate extremes and climate change: The Russian heat wave and other climate extremes of 2010. J. Geophys. Res., 117, D17103, https://doi.org/ 10.1029/2012JD018020.

Tsou, C.-H., and P. J. Smith, 1990: The role of synoptic/planetaryscale interactions during the development of a blocking anticyclone. Tellus, 42A, 174-193, https://doi.org/10.3402/ tellusa.v42i1.11869.

Zheng, M., E. K. Chang, and B. A. Colle, 2013: Ensemble sensitivity tools for assessing extratropical cyclone intensity and track predictability. Wea. Forecasting, 28, 1133-1156, https:// doi.org/10.1175/WAF-D-12-00132.1. 